\title{
PRODUTIVIDADE TOTAL E MUDANÇA TÉCNICA NA AGRICULTURA BRASILEIRA, PERÍODO 1955-1994
}

PEDRO HENRIQUE ZUCHI DA CONCEIÇÃO

Tese apresentada à Escola Superior de Agricultura "Luiz de Queiroz", Universidade de São Paulo, para a obtenção do título de Doutor em Ciências, Área de Concentração: Economia Aplicada.

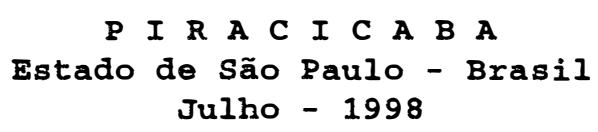




\section{Dados Internacionais de Catalogação na Publicação (CIP)}

\section{DIVISÃO DE BIBLIOTECA E DOCUMENTAÇÃO - Campus "Luiz de Queiroz"/USP}

\section{Conceição, Pedro Henrique Zuchi da}

Produtividade total e mudança técnica na agricultura brasileira, periodo 1955-1994 / Pedro Henrique Zuchi da Conceição. . - Piracicaba, 1998.

88 p. : il.

Tese (doutorado) - Escola Superior de Agricultura Luiz de Queiroz, 1998.

Bibliografia.

1. Agricultura 2. Brasil 3. Economia agricola 4. Inovação tecnológica 5.

Produtividade agricola 6 . Tecnologia agrícola 1. Título

CDD 338.0981 


\section{PRODUTIVIDADE TOTAL E MUDANÇA TÉCNICA NA AGRICULTURA BRASILEIRA, PERÍODO 1955-1994}

PEDRO HENRIQUE ZUCHI DA CONCEIÇÃO

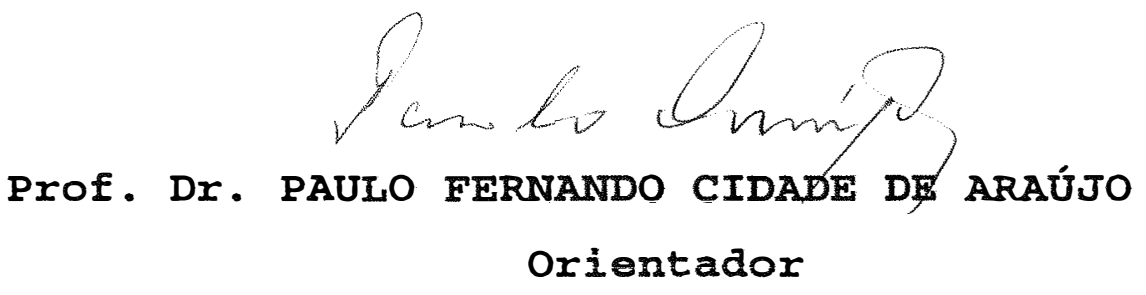




\title{
Ofereço
}

Ao meu pai, Pedro, cujo exemplo e saudade estarão sempre comigo

À minha mãe, Léa, amiga de todas as horas

Dedico

\begin{abstract}
À minha mulher Júnia Cristina, meu amor, sempre presente em todos os sonhos e conquistas
\end{abstract}

Ao meu pequeno grande Pedro vitor, minha alegria maior 


\section{A G R A D E C I M E N T O S}

Faço um agradecimento especial ao amigo Professor Paulo Fernando Cidade de Araújo. Sua dedicação, sinceridade e amizade foram de fundamental importância. Sem dúvida, um orientador muito especial.

Aos professores Dr. Carlos José Caetano Bacha, Dra. Miriam Rumenos Piedade Bacchi e Dr. Adriano J.B.V. de Azevedo Filho pelas valiosas contribuições indispensáveis para a realização deste trabalho, meus sinceros agradecimentos.

Ao professor Joaquim Guilhoto pelo apoio e estímulo ao longo do curso.

Aos amigos Alivínio de Almeida, Márcia Previtalle, Uilson Araújo pelos momentos alegres que desfrutamos juntos.

$$
\text { Ao amigo Alexandre Carvalho pelo }
$$
profissionalismo e dedicação na discussão do modelo econométrico deste trabalho. 
Ao amigo Azeredo que não mediu esforços para que este momento pudesse se concretizar. Pela amizade e dedicação, meu muito obrigado.

$\grave{A}$ Marilza e ao Denilson pelo incentivo e amizade. Ao amigo Roberto Dias pelas dicas, pelo entusiasmo e, sem dúvida, pelo apoio.

Destaco, ainda, o apoio do Departamento de Economia e Sociologia Rural da ESALQ/USP, da CAPES, da Secretaria Especial de Politicas Regionais e do Departamento de Economia da Universidade de Brasília.

A atenção e colaboração de Luciane e Silvana merecem meu destaque especial.

Aos funcionários do Departamento, à Elenice e à Maielli, pelo apoio ao longo do curso.

Aos amigos Ricardo, Sussy, João Ricardo, Maira, Mariana, D. Mercedes e Lineu pela alegre convivência em Piracicaba.

Aos meus irmãos, André, Ana, Júlio e Marco, pela torcida. Ao Jeremias e Dirce pelo incentivo.

Sem-dúvida, à minha esposa Júnia Cristina e ao meu filho Pedro Vitor que, em todos os momentos, sempre estiveram presentes com um sorriso, um abraço e um carinho. 


\section{SUMÁRIO}

\section{Página}

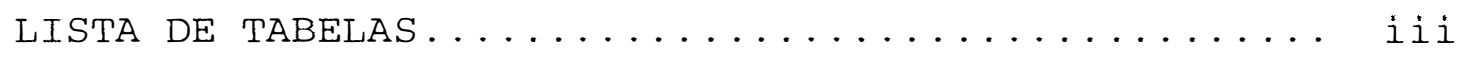

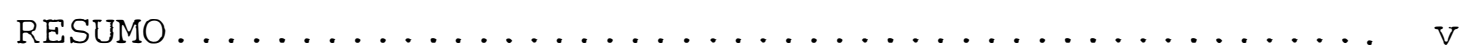

SUMMARY ................................. vi

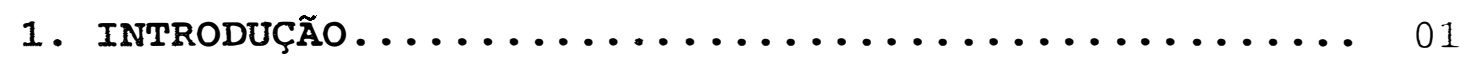

1.1 objetivos e estrutura da pesquisa.............. 05

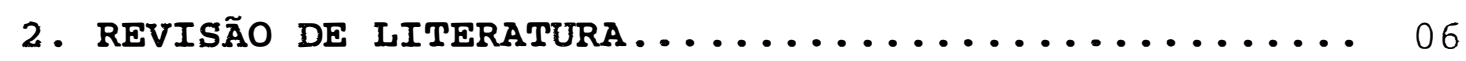

2.1. Agricultura brasileira em breve retrospectiva.. 06

2.2. Modernização e produtividade da agricultura ... 15

2.2.1. Análise e explicação do aumento da

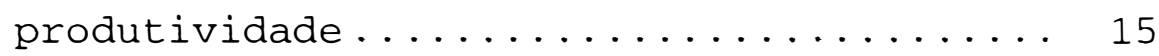

2.2.2. Mensuração da produtividade agrícola..... 23

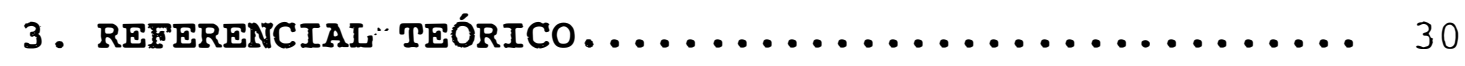

3.1. Análise através da função de produção......... 31

3.2. Análise através da função de custo........... 33

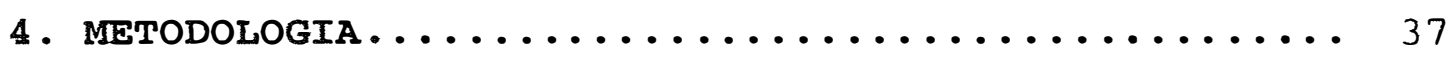

4.1. Estimativa das elasticidades relevantes: a

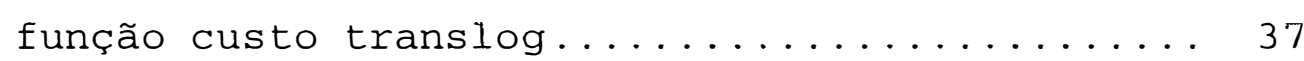

4.2. Definição das variáveis................ 41 


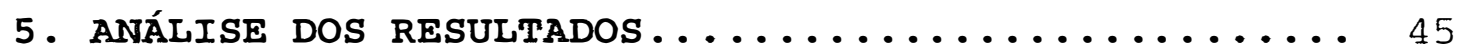

6. Conchusões........................... 54

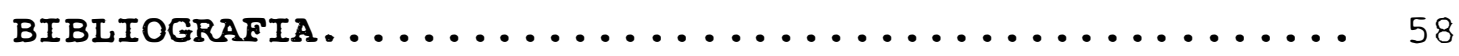

APÊNDICE 1: Índice de Divísia.............. 68

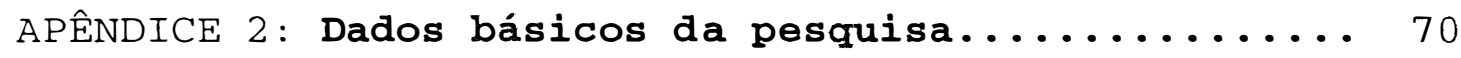

APÊNDICE 3: Estimativas dos parâmetros da função custo translog ................ 73

APÊNDICE 4: Elasticidades e retornos à escala, período $1955-1994 \ldots \ldots \ldots \ldots \ldots \ldots \ldots$........ 80

APÊNDICE 5: Estatísticas do modelo sUR Interativo.... 82 


\section{LISTA DE TABELAS}

\section{Tabela}

Página

1. Estimativa da elasticidade-custo em relação à produção, à utilização da capacidade e dos rendimento à escala. Valores médios do período 1955-1994. .................... 48

2. Produtividade total dos fatores na agricultura brasileira e sua decomposição. Valores médios do período 1955-1994. .......... 49

3. Taxa média de crescimento da utilização de insumos, de quantidade de produto e da capacidade de utilização na agricultura brasileira. Período 1955-1994.............. 51

4. Fontes de crescimento da produção agricultura brasileira. Valores médios do período 1955-1994.

5. Dados básicos para a estimação da função custo para a agricultura brasileira.

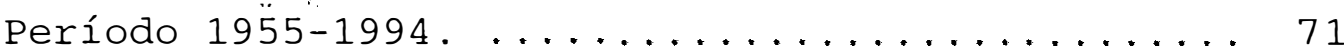

6. Participações observadas dos fatores no custo. Período 1955-1994.

7. Estimativa dos parâmetros da função custo translog, restrita, da agricultura brasileira. Modelo com a constante e a variável dummy. Período 1955-1994. 
8. Estimativa dos parâmetros das funções de parcela, terra e mão-de-obra, da agricultura brasileira. Modelo com a constante e a variável dummy. Período 1955-1994. . . . . . . . . . . . . . . . . . 75

9. Estimativa dos parâmetros da função custo translog, restrita, da agricultura brasileira. Modelo com a constante. Período 1955-1994. ...................... 76

10. Estimativa dos parâmetros das funções de parcela, terra e mão de obra, da agricultura brasileira. Modelo com a constante. Período 1955-1994. ............. 77

11. Estimativa dos parâmetros da função custo translog, restrita, da agricultura brasileira. Modelo sem dummy e sem constante. Período 1955-1994. ............ 78

12. Estimativa dos parâmetros das função de parcela, terra e mão-de-obra, da agricultura brasileira. Modelo sem dummy e sem constante. Período 1955-1994. ........... 79

13. Elasticidade-Custo e Retornos à Escala. Período 1955-1994. ..................... 81 


\title{
PRODUTIVIDADE TOTAL E MUDANÇA TÉCNICA NA AGRICULTURA BRASILEIRA, PERÍODO 1955-1994
}

\author{
Autor: Pedro Henrique Zuchi da Conceição \\ Orientador: Prof. Dr. Paulo Fernando Cidade de Araújo
}

\section{RESUMO}

o objetivo central do estudo é identificar a composição do índice de produtividade total da agricultura brasileira, considerando os efeitos decorrentes de progresso técnico, de economias de escala e da utilização da capacidade produtiva no período 19551994 .

A partir da estimação de uma função de custo translog para a agricultura foi possível obter a produtividade, utilizando o valor da elasticidade-custo em relação à produção, aos retornos à escala e à elasticidade-custo em relação à utilização da capacidade.

Os resultados demonstram que para o período 1955-1994 a produtividade total dos fatores cresce à taxa de 0,8\%a.a. Este crescimento é explicado pela existência de retornos à escala significativos e pela utilização da capacidade. 
No período 1955-1975, verifica-se uma taxa negativa de produtividade total (-1,19\%a.a.) influenciada pelo efeito negativo da taxa de mudança técnica, quando medida por seu efeito isolado.

No entanto, quando são analisados os períodos 1975-1994 e 1980-1994, já se observam os efeitos positivos da mudança técnica na taxa de produtividade total dos fatores. Ademais, são significativos os resultados de retornos à escala e utilização da capacidade.

O produto agropecuário, no período 19551994, cresceu à taxa de 2,59\% ao ano, superior ao crescimento dos insumos totais utilizados (1,78\% a.a.). Este fato só não foi observado no período 1955-1975, quando a utilização de insumos cresceu 3,77\% a.a. e a quantidade de produto, 2,58\% ao ano.

Resultado importante é o da contribuição da produtividade total dos fatores para explicar a produção agrícola. No período 1955-1994, cerca de 31\% do crescimento da produção são atribuídos aos ganhos de produtividade: Destaca-se, ainda, a importância da terra e do trabalho. que, juntos, respondem por aproximadamente $69 \%$ da taxa de produto.

No período 1975-1994, a importância da produtividade é muito maior e sua contribuição para o crescimento do produto atinge $71 \%$. 


\title{
TOTAL FACTOR PRODUCTIVITY AND TECHNICAL
}

\section{CHANGE IN BRAZILIAN AGRICULTURE, 1955-}

\section{PERIOD}

\author{
Author: Pedro Henrique Zuchi da Conceição \\ Adviser: Prof. Dr. Paulo Fernando Cidade de Araújo
}

\section{SUMMARY}

The main objective of this dissertation is to estimate total factor productivity in the Brazilian agriculture during the 1955-1994 period. Also, the study is an attempt to decompose the productivity index into its components, that is, technical change, returns to scale, and change in capital utilization (productive capacity).

The methodological approach used is the estimation a specific cost function for the agricultural sector as a whole. The decomposition framework and the interpretation of growth of total factor productivity are based on a method of directly linking the productivity index to key parameters of a translog cost function.

During the 1955-1994 period, the total factor productivity was found to have grown at $0.8 \%$ per annum; scale economies and productive capacity contributed positively for this result. The explanation for such a poor performance is given by the influence of a negative growth 
rate of total factor productivity in the first twenty years, 1955-1975, of the studied period.

In more recent periods, 1975-1994 and 19801994, the total factor productivity was found to have grown at $1.9 \%$ and $2.1 \%$ per annum, respectively. The decomposition of these rates indicates that all of their three components presented positive contributions. More important were the findings related to technical change: in the first period above, it contributed about $8 \%$, and in the second, this contribution was close to $34 \%$.

It was also found that total production of the Brazilian agriculture sector grew at $2.6 \%$ per annum in the 1955-1994 period. For this growth rate, about 31\% were explained by total factor productivity growth, while land and labor, together, contributed about 69\%. In the 1975-1994 period, however, the total productivity index explained $71 \%$ of the output growth rate.

The results of this study support the view that, in ourdays, factor productivity is a relevant determinant for the growing process of the Brazilian agriculture. 


\section{INTRODUÇÃO}

Os ganhos de produtividade que a agricultura brasileira acumula no tempo podem ser decorrentes de progresso técnico, de economia de escala e de maior utilização da capacidade produtiva. O melhor conhecimento desses determinantes dos ganhos de produtividade é questão essencial no processo de crescimento ou desenvolvimento econômico.

O crescimento econômico de um país pode ser definido como a expansão a longo prazo da capacidade de prover a população com bens econômicos cada vez mais diversos, capacidade esta baseada no avanço da tecnologia e nas adaptações institucionais e políticas que a sociedade requer (Kuznets, 1985). Ainda segundo o autor, o desenvolvimento da tecnologia é uma das principais fontes de crescimento" econômico, mas é apenas uma fonte potencial, condição necessária mas não suficiente. Para que a tecnologia seja eficiente e, de fato, para que sua utilização estimule seu próprio desenvolvimento, devem ser feitas adaptações institucionais e políticas, pois são estas que determinam o uso apropriado das inovações geradas pela acumulação contínua do conhecimento humano. 
Kuznets (1974) afirma que o moderno crescimento econômico, analisado por alguns indicadores convencionais, mostra uma evolução múltipla das taxas de produtividade dos fatores, sendo estas alteradas muitas vezes pelo avanço tecnológico.

O crescimento da produção de uma economia, de uma indústria ou de uma empresa é determinado pelo aumento no uso dos fatores de produção e/ou por variações na eficiência (produtividade) com que esses recursos são utilizados. Desde os trabalhos de Solow (1957), Kendriek (1961) e Deninson (1962), são numerosos os estudos empíricos preocupados com a mensuração da produtividade dos fatores, com a identificação de seus determinantes e sua contribuição para o crescimento do produto.

A análise dos processos de mudança na composição da produção, substituição de fatores e progresso técnico, experimentados pela agricultura brasileira, com efeitos diretos sobre a produtividade agrícola, também tem concentrado crescente esforço dos economistas nos últimos anos.

Segundo Brandão \& Alves (1993), o principal desafio futuro da agricultura é o da modernização. De forma completamente distinta do que ocorreu na década de 80, a demanda de alimentos aumentará substancialmente em resposta à redinamização da economia. O progresso técnico será o elemento-chave para conciliar os interesses de produtores e consumidores que buscam, respectivamente, retornos mais elevados para a produção e preços mais baixos para alimentos e matérias primas. Em outras palavras e em termos 
mais abrangentes, o crescimento da produtividade total da agricultura e das produtividades parciais do trabalho e da terra desempenham importante papel no processo de aceleração da taxa de crescimento da economia brasileira.

Em recente trabalho, Gasques \& Conceição (1997) analisam a produtividade total da agricultura, no período 1976-1994, que teria atingido a taxa de crescimento de 3,88\% a.a.. Observam que em período mais recente, 19861994, esta taxa cai para 3,11\% a.a.. Este fato pode ser preocupante, pois ocorre num momento em que os ganhos de produtividade são considerados condição essencial para a garantia da competitividade do setor. Ainda segundo os autores, as taxas de crescimento das produtividades parciais do trabalho e da terra apresentam o mesmo comportamento do índice de produtividade total - tendência declinante - assumindo taxas de 2,21\% a.a. e de 3,23\% a.a., respectivamente, no período 1986-1994. Segundo esta análise, o que mais preocupa é a queda da taxa de crescimento da produtividade do trabalho, a qual, no período 1976-1994, crescia à taxas de 4,02\% ao ano.

Na realidade, o processo de desenvolvimento da agricultura. não consiste apenas em transformar um setor estagnado em setor dinâmico moderno, mas sim em acelerar as taxas de crescimento da produção e da produtividade, de modo compatível com o crescimento de outros setores da economia.

De acordo com a teoria da modernização, o setor agrícola poderá transformar-se de tradicional em moderno e dinâmico, capaz de impulsionar o desenvolvimento, 
mediante mudanças tecnológicas. A adoção de insumos modernos e a melhoria do nível de educação viabilizariam a mudança tecnológica, garantindo maior produtividade dos fatores de produção e taxas de retorno mais elevadas, possibilitando, assim, a geração de excedentes de produto, de fatores e de mercado (Kuznets, 1964).

Por seu turno, a simples constatação de altos índices de produtividade dos fatores na agricultura não permite afirmar que tais índices estejam, necessariamente, relacionados com a transformação do setor em função do progresso técnico. Neste contexto, a decomposição do indicador de produtividade total passa a ser, também, de fundamental importância para a determinação dos instrumentos de política econômica que irão sustentar o crescimento do setor.

É neste cenário que se qualifica a oportunidade e a importância de estudos que possam contribuir para o conhecimento do processo de modernização da agricultura brasileira, principalmente se esses estudos focalizarem a identificação de mudança técnica. Além disso, eles deverão enfatizar o comportamento dos indicadores de produtividade e seus fatores determinantes. 


\subsection{Objetivos e estrutura da pesquisa}

o objetivo geral do estudo é estimar e decompor a taxa de crescimento da produtividade total dos fatores da agricultura brasileira, no período 1955-1994.

Especificamente, pretende-se:

a) estimar a função custo translog para a agricultura;

b) calcular a produtividade total dos fatores da produção (PTF);

C) determinar os efeitos do progresso técnico, de economias de escala e de utilização da capacidade produtiva na produtividade total dos fatores; e,

d) estimar a contribuição da produtividade total e do uso dos fatores na determinação do produto agropecuário.

Além desta introdução, o estudo está estruturado em mais 5 capítulos. Uma revisão de literatura é apresentada no Capítulo 2 e proporciona a base da fundamentação teórica e metodológica discutidas nos capítulos 3 e 4. A análise dos resultados está no Capítulo 5 e, no Capítulo 6, são apresentadas as conclusões da pesquisa. 


\section{REVISÃO DE IITERATURA}

Neste capítulo de revisão de literatura, faz-se inicialmente breve retrospectiva sobre a agricultura no período em estudo. Em seguida, são enfatizados algumas contribuições relevantes à modernização e produtividade do setor.

\subsection{Agricultura brasileira em breve retrospectiva}

A modernização da agricultura vem se processando desde o pós-guerra, embora a tecnologia agrícola utilizada na maior parte do país ainda fosse bastante rudimentar até meados da década de 60. As exceções estavam nos Estados de São Paulo e Rio Grande do Sul que concentravam, por exemplo, $44 \%$ e 25\%, respectivamente, do total de tratores do país. O número de estabelecimentos com algum tipo de implemento moderno era muito reduzido na fase anterior à expansão do parque industrial (Martine, 1990) .

Diversos eventos atuaram para modificar a estrutura e o perfil da produção agrícola a partir de 1965. A consolidação do parque industrial, a institucionalização do crédito rural e de outros incentivos à produção, a 
internacionalização do pacote tecnológico da Revolução Verde e a melhoria dos preços internacionais são fatores que começam a modificar o padrão de desenvolvimento da agricultura que, segundo Alves \& Contini (1992), se encontrava marginalizada do processo de transformação da economia brasileira.

Para Barros \& Manoel (1992) a política de crédito rural subsidiado, cujas disponibilidades reais cresceram a taxas elevadas, a relação favorável entre preços de produtos agrícolas e de insumos modernos (de um lado) e preços agrícolas vis-à-vis preços industriais (de outrol e o incentivo dado à substituição de importações acabaram por favorecer o setor e consolidar a estratégia de modernização em especial na década de 70 .

A partir dos meados da décadas de 60 e até final da década de 80, a agricultura brasileira atravessa um forte processo de transformação, crescendo a taxas expressivas, alterando as fontes de crescimento, uma vez que a produtividade da terra e do trabalho passam a fazer parte da dinâmica do setor, além de alterar o 'mix' de produção. Não se deve negligenciar o fato de que este processo não ocorre de forma homogênea nas diversas regiões e para o conjunto dos produtos.

No entanto, essas transformações foram possibilitadas, em grande parte, por uma estratégia bem definida de modernização agrícola. O eixo central desta estratégia foi a expansão do crédito rural subsidiado destinado à aquisição de insumos modernos, aliada a um processo intenso de substituição de importações, tanto na 
área mecânica, quanto na área química de insumos agrícolas (Barros, 1983).

Este processo contribui para a consolidação do setor de insumos modernos que se desenvolve na esteira da expansão da área plantada, dos incentivos à produção doméstica de insumos, do incremento do volume de crédito seletivo e por meio da dinamização das exportações agrícolas favorecidas por um mercado externo francamente em expansão (Barros \& Manoel, 1992).

Vale ressaltar que a política agrícola quase sempre procurou subordinar o crescimento do setor ao atendimento de objetivos de equilíbrio interno e externo da economia como um todo. Portanto, tendo em vista a transformação do papel da agricultura brasileira no processo de desenvolvimento, que deixa de ser um problema de crescimento para ser de estabilidade, desloca o interesse para a política macroeconômica, definindo assim um novo padrão de desempenho do setor primário.

Este fato pode ser observado no trabalho de Barros (1979), que analisa o desempenho da agricultura brasileira no período de 1960 a 1974, e conclui que a política agrícola é acima de tudo subordinada ao equilíbrio de curto prazo. portanto, pouco se avançou em termos de três fontes de crescimento: a melhoria do capital humano do setor, avanços na área biológica e maior oferta de infraestrutura.

Os instrumentos e as linhas de ação da política agrícola pouco se alteraram durante o período 1974-1979. Neste intervalo, ocorreu apenas uma modificação 
de prioridade, onde a política de insumos se traduziu em crédito e substituição de importações e a política de preços continuou a exercitar o difícil equilíbrio entre baixos preços nas cidades e boa remuneração às exportações.

Deve-se destacar a importância da política de crédito rural subsidiado como fator de estímulo a adoção de inovações tecnológicas, tanto biológicas como mecânicas. Segundo Araújo \& Meyer (1979) é difícil avaliar a importância do crédito no financiamento de insumos modernos para a agricultura, embora os programas de crédito tenham sido muito expressivos em termos de volume financiado. Ressalta-se, portanto, a importância da política em torno da estratégia de modernização, evidenciando o poder regulador do Estado no âmbito da política monetária.

Apesar da condução de agressiva política de crédito para o setor, observa-se durante as décadas de 60 e 70, modernização parcial do setor com ganhos de produtividade concentrados em alguns produtos e regiões com uma certa segmentação setorial.

Mesmo com a existência 'secular' de problemas na agricultura, a mudança de rumos, ou seja, a melhor compreensão sobre o papel da modernização só acontece de forma sistemática a partir do início da década de 70, quando, no âmbito federal e estadual, se consolidaram as instituições de ensino, pesquisa e extensão rural e os instrumentos de política econômica com o objetivo de incrementar a produtividade. Registro especial, neste sentido, deve ser feito à criação da Empresa Brasileira de Pesquisa Agropecuária - EMBRAPA, em 1973, 
cujos investimentos em capital humano e inovações tecnológicas muito contribuíram para as mudanças no padrão tecnológico da agricultura.

O desempenho do setor agrícola no período 1950-1979 foi satisfatório, apesar das grandes deficiências estruturais. Isto, devido, basicamente, à expansão da fronteira agrícola, às condições favoráveis no mercado internacional de algumas commodities e à disponibilidade de crédito rural.

A década de 80 caracterizou-se pelo baixo crescimento econômico, pelo crescente descontrole fiscal e monetário, materializado na elevação das taxas de inflação, e pelo empobrecimento de enorme parcela da população brasileira. As políticas econômicas setoriais tornaram-se refém da instabilidade macroeconômica, a qual também contribuiu para reduzir o horizonte de planejamento do governo e os investimentos na produção de bens públicos (Brandão \& Alves, 1993).

Vários foram os fatores determinantes da instabilidade econômica, fatores esses que podem ser agrupados em exógenos e endógenos. No que diz respeito aos fatores exógenös devem-se registrar a influência da demanda externa, as condições climáticas, o choque externo representado pela crise do petróleo de 1979 e a elevação das taxas de juros internacionais no início da década de 80. Entre os fatores endógenos, estão as políticas dirigidas aos setores industrial, agrícola e comercial que foram muito instáveis na década 80. Com efeito, na medida em que a instrumentação da política econômica foi regida 
por uma contraposição entre ortodoxia e heterodoxia, tal fato acabou gerando um componente de instabilidade na comercialização agrícola, nos investimentos rurais e na produção industrial de insumos modernos para o setor.

Assim sendo, as políticas de estabilização produziram impactos sobre a agricultura, através da redução da disponibilidade de crédito e elevação das taxas de juros. Segundo Almeida (1994), no período 1979-1993 verifica-se uma queda real de $11 \%$ a.a. no volume de crédito rural concedido. Esta tendência declinante pode ser estendida até 1997 (Araújo et al., 1998).

A este fato, associa-se a remoção do subsídio e a redução dos gastos públicos com pesquisa e extensão (Lopes, 1987).

A despeito de enfrentar instabilidades freqüentes, em termos agregados, a agricultura foi um setor dinâmico da economia brasileira, atingindo taxas de crescimento da ordem de 3,56\% a.a. no período 1980-1989, ora respondendo a estímulos de políticas voltadas para solução de problemas externos, ora para reduzir pressões internas (Homem de Melo, 1990).

Vale ressaltar, ainda, que o padrão de estagnação da economia brasileira que caracterizou a década de 80 não deve ser estendido de forma generalizada ao setor agrícola. Enquanto o PIB industrial real cresceu 3,84\% no período 1980-1990, o PIB real da agricultura elevou-se em $28,2 \%$. Isso corresponde a uma taxa média anual de 2,5\% para a agropecuária e de 0,38\% para a indústria (Dias \& Barros, $1998)$. 
Fato marcante desta década é que não se pode mais compreender a estrutura e a dinâmica da agricultura brasileira sem levar em conta a estrutura e a dinâmica dos setores industriais com ela interrelecionados, bem como as formas e características das ligações que se estabelecem entre eles. Passa a existir não mais uma agricultura, e sim, vários complexos, com suas especificidades sujeitas a ajustes e ações frente às oscilações da política econômica.

Na medida em que a economia passa a ser cada vez mais industrializada, as interdependências entre atividades rurais, indústria e serviços reforçam as funções da agricultura no desenvolvimento econômico. Os vínculos de interdependência ampliam-se na proporção em que a agricultura se torna absorvedora do progresso técnico industrial e esta se adapta às necessidades da agricultura, fornecendo-the insumos e adquirindo matérias-primas. A interação entre os setores é função da agroindustrialização e da adoção de inovações na agricultura, bem como da diversificação da produção agrícola.

Nesta nova fase, os produtos agrícolas se transformam em iǹsumos para outros setores produtivos, influenciando de forma decisiva a formação dos preços, das margens e dos lucros do setor. As relações entre agricultura e consumidores finais encontram os agentes intermediários da cadeia produtiva.

$$
\text { Segundo Dias (1993), essas relações }
$$

determinam os caminhos para uma politica de fomento à produção agrícola para a década de 90. A concentração agroindustrial numa região passa a ser pré-condição para a 
expansão da produção agropecuária, assim como para sua especialização. Os instrumentos de incentivo agrícola deixam de ser o preço mínimo ao produtor e a política de crédito, passando a incluir a política industrial e os serviços essenciais de infra-estrutura.

Neste sentido, os instrumentos tradicionais de políticas públicas devem ser reservados aos produtos com menor transformação industrial, com menor acesso ao mercado internacional e/ou de grande importância para o consumo básico da população, em especial para os segmentos de baixa renda. Ainda segundo Dias, o financiamento de longo prazo para a capacitação tecnológica é uma alternativa adequada de política em substituição aos estímulos de elevada proteção tarifária.

Logo, a nova fase de desenvolvimento e a consolidação do processo de estabilização econômica deverão contribuir de forma decisiva para o crescimento deste setor agro-industrial da agricultura. Verifica-se uma retomada do crescimento da produção agrícola nos anos de 1993/96 da ordem de 7,7\%, que segundo Bacha \& Rocha (1998), decorre principalmente da 'elevação da produtividade da terra. Ao longo desta última década, está ocorrendo uma recuperação dà participação da agricultura no PIB fruto da melhoria das relações de troca (preços recebidos/preços pagos) e dos ganhos de produtividade que o setor vem apresentando.

Verifica-se, também, uma combinação de fatores estruturais neste processo de melhoria da produtividade das principais culturas, entre eles: i) reorganização espacial dos principais cultivos em terras 
mais aptas, aliada ao menor ritmo de expansão da fronteira agrícola; ii) redução dos custos da mão-de-obra; e, iii) melhor utilização dos insumos modernos (Silva, 1993). A incorporação de inovações de processos, e não apenas agronômicas mas também de formas de organização e gerenciais, contribuem também para os ganhos de produtividade.

Ao longo das últimas décadas diversas transformações aconteceram no setor agrícola nacional. Hoje, tem-se a convicção de que o aumento da produtividade dos fatores de produção é de fundamental importância para o crescimento sustentável da produção agrícola. No entanto, o estabelecimento de ganhos de produtividade depende da forma como os instrumentos de política agrícola de longo prazo, em especial a pesquisa, serão acionados.

-Finalmente, vale ressaltar que o processo de modernização pode ter gerado grandes vieses, tais como concentração dos recursos entre médios e grandes produtores, entre indústrias de insumos, máquinas e implementos e entre agro-indústrias processadoras de matérias-primas. Distorções entre regiões, culturas e produtores foram também observadas no curso do processo de modernização. Portanto, realizar a transição para um novo modelo de desenvolvimento, reduzindo essas distorções, constitui enorme desafio a ser enfrentado pelos formuladores de políticas públicas. 


\subsection{Modernização e produtividade da agricultura}

Duas questões têm sido amplamente debatidas no âmbito da agricultura. Uma refere-se à análise e explicação do aumento da produtividade. Outra diz respeito à mensuração da produtividade agrícola.

\subsubsection{Análise e explicação do aumento da produtividade}

Os trabalhos que procuram explicar o comportamento da produtividade agrícola têm forte ligação com a teoria da modernização na medida em que esta objetiva identificar os fatores determinantes dos aumentos de produção e produtividade das atividades agropecuárias. Ou seja, através do estímulo à utilização de insumos modernos e à mecanização das lavouras, as quais, por sua vez, afetam de forma expressiva a composição da produção e a utilização dos fatores produtivos.

Neiste sentido, países ou regiões que apresentam uma agricultura atrasada e tradicional devem sofrer transformações, através da modernização das técnicas agrícolas, tornando esse setor voltado para o mercado e habilitando-o a impulsionar o desenvolvimento econômico (Schultz, 1965). Portanto, um esforço no rumo da modernização, a partir da adoção de técnicas modernas, seria capaz de modificar este cenário. 
Ainda segundo Schultz, a agricultura tradicional tem as seguintes características: i) desestímulo à poupança e investimento, tendo em vista a reduzida taxa de retorno aos investimentos; ii) com o passar do tempo, tende a um equilíbrio estacionário; iii) baixa produtividade da mão-de-obra; iv) poucas ineficiências na distribuição dos fatores de produção; e, v) estado do conhecimento permanecendo constante.

$\mathrm{Na}$ caracterização da agricultura tradicional, rejeitam-se explicações baseadas em atributos culturais, arranjos institucionais ou propriedade técnica dos fatores. Na perspectiva de transformar a agricultura, Schultz (1965) destacou dois elementos fundamentais. O primeiro refere-se à necessidade de os países com agricultura tradicional investirem na criação de novos fatores de produção agrícola, suficientemente lucrativos, para serem adotados pelos agricultores. Esta preocupação opõe-se às idéias de que já existem conhecimentos técnicos suficientes para um substancial aumento de produtividade agrícola, bastando apenas a difusão desses conhecimentos entre os produtores. Apesar de já existirem, embora não aplicáveis às condições de agricultura tradicional, a utilização dos insumos ditos modernos requer investimentos em pesquisa elou experimentação agronômica de forma a adaptá-los às novas condições sociais e ambientais.

O segundo elemento essencial, na perspectiva de modernização, refere-se às habilitações dos agricultores ou, em outras palavras, ao investimento em capital humano, sobretudo em instrução, treinamento no trabalho e melhoria na saúde. O investimento em capital humano, além de 
apresentar elevadas taxas de retorno privado e social, viabiliza todo o processo de modernização por ser a principal fonte desse processo.

Schultz (1965) procurou, desta forma, mostrar que esta transformação torna-se possível através de investimentos em pesquisa básica e na geração de conhecimentos tecnológicos que ofereçam expressivos retornos econômicos. Afirmou, ainda, a necessidade de utilização de insumos modernos, dando à educação papel de destaque na formação de pesquisadores e na habilitação dos produtores rurais, capacitando estes últimos a empregar, adequadamente, os insumos modernos.

A intensificação da pesquisa agrícola, complementada pela difusão dos conhecimentos gerados e dos novos insumos, sustentaria a estratégia básica do desenvolvimento. Como resposta à difusão de conhecimentos e uso de insumos modernos, ocorreriam o aumento da produtividade e o crescimento da renda agrícola. Logo, o agricultor tem seu papel destacado como agente de transformação sensível aos programas de desenvolvimento, desde que a tecnologia disponível seja apropriada às condições existentes.

A mudança tecnológica passa a ser analisada como fator endógeno do processo de desenvolvimento a partir dos estudos desenvolvidos por Hayami \& Ruttan (1985). A mudança tecnológica é direcionada pela dotação de fatores e por seus preços relativos. Se a demanda de produtos agrícolas aumentar com o crescimento populacional e de renda, os preços dos fatores com ofertas inelásticas 
elevar-se-ão relativamente aos dos fatores com ofertas elásticas, tornando mais lucrativas as inovações que poupam os fatores escassos. De modo geral a inovação mecânica poupa mão-de-obra, enquanto as inovações químicas e biológicas poupam o fator terra.

Os processos de modernização e de expansão agrícola do Japão e dos Estados Unidos são exemplos concretos, citados por Hayami \& Ruttan (1985), de que as inovações tecnológicas na agricultura são induzidas pela disponibilidade relativa de fatores na economia. No Japão, a tecnologia tendeu inicialmente a ser poupadora de terra, dada a escassez desse fator. Por sua vez, nos Estados Unidos, que apresentavam escassez de mão-de-obra, a tecnologia tendeu a ser poupadora deste fator. No caso brasileiro este processo não se verificou, conforme destaca o estudo de Santos (1986).

Uma vez que o desenvolvimento tecnológico responde aos sinais recebidos dos mercados de fatores de produção, o sistema de pesquisa agrícola funcionaria em resposta aos sinais emitidos pelo mercado. Neste contexto, os sinais são per̀cebidos rapidamente pelo setor privado gerador de pesquisas, enquanto no setor público isto ocorre de modo mais lento, através da ação dos grupos de pressão. Neste ponto, Hayami \& Ruttan (1985) deram, também, uma importante contribuição ao avanço científico, ao atribuírem ao setor público papel de destaque na geração das inovações tecnológicas para a agricultura dos países em desenvolvimento. 
Vale ressaltar, conforme argumentam Cavallo \& Mundlak (1982), que a mudança tecnológica não ocorre em resposta apenas aos movimentos dos preços dos fatores de produção, mas também em função do estoque de capital disponível. À medida que se intensifica o processo de acumulação de capital, cresce o uso de técnicas intensivas no uso desse fator, mesmo sem ocorrer alteração na razão dos preços. O estoque de capital na economia ou setor pode ser, portanto, limitante ou determinante na escolha da tecnologia.

De Janvry (1978) também questiona o processo de geração de novas tecnologias, em resposta apenas aos sinais emitidos pelo mercado (preços relativos dos fatores de produçãol e enfatiza que ele depende da pressão exercida por grupos sociais de interesse comum. Esse processo é dinâmico e interativo, e nele as estruturas sócio-econômica e a político-burocrática desempenham papéis fundamentais. Uma vez definida a demanda efetiva por inovações, esta é 'transmitida" às instituições de pesquisa, que a ela respondem ofertando inovações especificas.

O resultado do esforço do desenvolvimento tecnológico, fundamental para a transformação de uma agricultura tradicional em moderna e auto-sustentável, produz alguns tipos de tecnologia cujos benefícios não podem ser diretamente apropriados pelas instituições geradoras, razão pela qual não interessam ao setor privado. Neste sentido, Homem de Melo (1980) chamou atenção para o fato de alguns produtos de pesquisa agrícola apresentarem características de bens públicos ou, pelo menos, de bens com elevados efeitos externos. Podem ser observadas 
externalidades entre produtores, consumidores ou entre esses dois grupos, desde que haja interdependência entre as ações de indivíduos ou firmas e não-compensação monetária entre as partes envolvidas.

A dificuldade de apropriação dos ganhos provenientes dos novos conhecimentos decorre das dificuldades de uso do sistema de patentes, ou seja, excluir os não-pagantes, que são usuários desses conhecimentos ${ }^{1}$. Em decorrência da existência de pesquisas com características de bem público, surgem problemas relacionados com a quantidade ofertada dessas pesquisas que, certamente, seria inferior à ótima, caso a questão fosse deixada ao livre arbítrio das forças de mercado. É que os ganhos privados seriam menores que os ganhos sociais. Nesta circunstância, a participação do setor público é imprescindível e o setor agrícola é rico em exemplos dessa natureza, sobretudo em inovações sobre época de plantio, espaçamento, melhoramento e conhecimento genético básico.

Outro aspecto importante na análise do processo de geração e adoção de novas tecnologias diz respeito à incerteza do lucro com os resultados da pesquisa, bem como à distribuição diferenciada dos ganhos resultantes da pesquisa. Produtos com alta elasticidadepreço de demanda, cujos benefícios ficam principalmente com os produtores, são preferidos no processo de inovação, implicando maior pressão dos agricultores junto às entidades geradoras de pesquisa. Exemplo disto é o caso de

1 Só recentemente foi aprovada no Brasil a Lei dos Cultivares. 
produtos de exportação em países considerados pequenos em relação ao mercado internacional e, por isso, o preço é dado independentemente da quantidade exportada por esses países. Assim, para produtos com baixa elasticidade-preço de demanda os ganhos decorrentes da pesquisa são distribuídos entre produtores e consumidores. Os ganhos dos consumidores, medidos pelo acréscimo do excedente do consumidor, são sempre positivos, mas o acréscimo do excedente do produtor pode ser positivo ou negativo. É o que ocorre com certos produtos de consumo doméstico. Assim sendo, para estes produtos seria esperada uma pressão bem menor dos agricultores por geração de inovação tecnológica.

Até aqui, foi considerado apenas o processo de geração de tecnologias. Entretanto, o retorno efetivo das inovações depende da geração e da adoção da tecnologia, e esta preocupação é fundamental. O processo de adoção, ou seja, a passagem da tecnologia ofertada para a matriz de retornos efetivos está sujeita à ação da estrutura sócioeconômica. Nesta estrutura, podem-se destacar os seguintes elementos: a) posse da terra; b) estágio tecnológico; c) preços de produtos e fatores; d) acesso a instituições como crédito, sistemas de informação e educação.

O modelo de De Janvry amplia a questão de grupos de pressão mencionada no modelo de inovação induzida de Hayami e Ruttan, colocando-a em termos da estrutura político-burocrática, e destacando a importância da estrutura sócio-econômica na passagem da tecnologia ofertada para a matriz de retornos efetivos. Ou seja, o modelo considera todo o processo de oferta e demanda de inovação e inclui geração e adoção de tecnologias. 
A literatura tem apontado que, no Brasil, a geração de novas tecnologias é devida não só aos sinais emitidos pelo mercado, mas também à atuação de grupos de pressão (Monteiro, 1984).

Os grupos sociais podem influir na decisão política através dos mecanismos de pressão. Quanto maior o grau de organização do grupo, maior o poder de pressão sobre a estrutura político-burocrática na defesa de seus interesses. Esses grupos de maior poder de pressão têm maior acesso às instituições de crédito, educação e informação.

Por outro lado, a geração de novas tecnologias pode ser tendenciosa na direção de determinadas culturas, mais lucrativas que outras. Nesse contexto, as culturas que mais se beneficiam são as do subsetor exportador e/ou energético, por apresentarem vantagens no que se refere a preços mais estáveis, ao volume de crédito e aos subsídios.

A distribuição desigual de crédito entre produtos e produtores pode ter contribuído, de certa forma, para o agravamento da concentração da posse de terra no País. O favorecimento de determinadas culturas, que se apresentaram mais lucrativas, pode ter colaborado para a substituição de culturas menos lucrativas por outras, de maior importância na balança comercial. E a desestruturação do emprego no campo pode ter-se acentuado, a partir da mudança ocorrida na escala de produção e na concentração fundiária. 


\subsubsection{Mensuração da produtividade agrícola.}

A mensuração da produtividade tem sido analisada através da produtividade da terra e da produtividade do trabalho. A mensuração da produtividade dos fatores de produção, reflexo do progresso técnico, tem merecido estudos em diversos países, com o objetivo de determinar a evolução da modernização da agricultura ao longo dos anos.

Hoffmann \& Jamas (1990), Kageyama (1986), Kageyama \& Graziano Da Silva (1983), Campos (1982), Aguirre \& Bacha (1989), por exemplo, discutem as relações entre crescimento e produtividade do trabalho e da terra, a partir do conceito de produtividade parcial.

Analisando a produtividade da terra e do trabalho em 332 microrregiões homogêneas das regiões Nordeste, Sudeste, Sul e Centro-Oeste, nos anos de 1975 e 1980, Hoffmann \& Jamas (1990) concluem que em geral as produtividades dos fatores cresceram, exceto as do Estado do Paraná. Realçam ainda a existência de uma correlação positiva entre as duas medidas.

Kageyama \& Graziano Da Silva (1983) afirmam, a partir da análise dos indicadores de produtividade parcial, que o progresso técnico tem-se traduzido na agricultura brasileira em substanciais acréscimos de produtividade. Esses autores tentam relacionar, também, a questão do progresso técnico com a evolução do nível de emprego no meio rural. Kageyama (1986) discute e apresenta uma forma de ponderação da mão-de-obra rural segundo o sexo 
e a idade, indicando ainda as dificuldades para se obter uma medida em equivalente-homem para estimar a produtividade do trabalho.

Os aumentos da produtividade da terra, analisados por Campos (1982) nos anos 70 e 80 , são significativos para explicar o crescimento da produção. O autor mostra que a produtividade da terra apresentou comportamento diferenciado, sendo desfavorável para o subsetor de produção de alimentos para o mercado interno em relação às culturas de exportação.

Aguirre \& Bacha (1989) concluem que 0 crescimento do produto agrícola, na década de 80 , deveu-se fortemente ao crescimento da produtividade do trabalho, podendo esse crescimento ser explicado basicamente por mudanças nas características dos bens de capital ou pela melhor divisão do trabalho na agricultura.

No entanto, Hoffmann \& Jamas

(1990)

reconhecem que algumas distorções, como alteração climática e imperfeições no mercado, podem modificar o valor agregado da produção agrícola e, por conseguinte, o valor do índice de produtividade, sem que esteja ocorrendo de fato mudança técnica.

A segmentação da agricultura brasileira, reconhecida por Homem de Melo (1978) e por Barros \& Grahan (1978), acaba por se refletir, também, na produtividade de cada grupo de culturas. A diferenciação da agricultura, segundo esses autores, baseou-se fundamentalmente no processo de formação de preços. A principal implicação da existência de duas categorias de bens é que para os 
produtos exportáveis os preços tendem a se manter estáveis, enquanto no caso dos domésticos as variações de oferta tendem a produzir acentuadas flutuações de preços. Este fato não só contribui para dificultar o processo de adoção de novas técnicas, como também restringe os ganhos de produtividade dos fatores terra e trabalho.

Nos estudos de Schuh \& Alves (1971), Alves \& Pastore (1977) e de Silva, Fonseca \& Martin (1980), a contribuição do aumento da produtividade para 0 crescimento da produção agrícola depende de como os instrumentos de política econômica de longo prazo foram acionados no passado, com destaque para a política de pesquisa agrícola. Daí as grandes diferenças de produtividade entre regiões, grupos de cultura e categorias de produtos.

Christensen (1975) e Alves (1979) reconhecem a importância desta abordagem, porém não a consideram suficiente para explicar o processo de mudança técnica. Alves chama a atenção para o fato de que o comportamento de um índice parcial de produtividade pode estar sinalizando uma direção diferènciada da que seria observada se fossem considerados todos os insumos no cálculo do indicador de produtividade total.

Vera $\mathrm{F}^{\mathbf{Q}}$ \& Tollini (1979) também defendem $\mathrm{O}$ uso de um índice agregado como medida mais racional de produtividade, apontando o erro que se pode incorrer ao comparar a produtividade da terra, ou do trabalho, entre países e regiões. 
Belrens \& Haen (1980) estudam a obtenção dos índices de produtividade total dos países da Comunidade Econômica Européia, onde se destacam, no período de 1963 76, Holanda, Alemanha e Irlanda com os maiores níveis de produtividade. Esses autores discutem, também, a impropriedade da utilização de indicadores de produtividade parcial.

Silva (1982) discute as limitações do uso de índices parciais, procurando superar as deficiências das informações. Para tanto, realiza investigação empírica sobre o progresso tecnológico da agricultura paulista através de um índice de produtividade total.

Utilizando o conceito de produtividade total, Hayami \& Yamada (1983) buscam identificar as origens do progresso técnico no Japão, no período de 1878-1962. Concluem que a cronologia do progresso tecnológico na agricultura japonesa é explicada em termos de acumulação e difusão do conhecimento técnico.

Silva \& Carmo (1986) focalizam os conceitos de produtividade parcial, total e progresso técnico na agricultura, discutindo os problemas de mensuração dos índices com bäse na teoria dos números-índices. Realizam comparação dos indicadores obtidos para a agricultura paulista com os de outros países desenvolvidos e em desenvolvimento. Os autores utilizam os números-índices de Laspeyres, Paasche, Fischer e Tornqvist nos cálculos dos indicadores de produtividade da terra, do trabalho e total da agricultura paulista. Comparações internacionais dos 
indicadores de produtividade total dos fatores são também alvo de análise do estudo de Evenson (1992).

Analisando o crescimento agrícola do sul da Ásia, Rosegrant \& Evenson (1992) discutem as fontes de crescimento da produtividade e estimam taxas de retorno do investimento público em pesquisa e extensão. Utilizam o indice de Tornquist-Theil para o cálculo da produtividade total, o qual assume competição perfeita, retornos constantes à escala e tecnologia Hicks-neutra.

Ávila \& Evenson (1995) também estimam os indicadores de produtividade total dos fatores para a agricultura brasileira. Analisam a produtividade total dos fatores por região no periodo de 1970-85. As regiões Centro-Oeste e Sudeste apresentam as taxas mais elevadas, em função da expansão da fronteira agrícola nos cerrados e das inovações tecnológicas incorporadas ao processo produtivo nessas regiões.

É importante observar que os trabalhos anteriormente citados nesta revisão utilizam, para medir a produtividade dos fatores na agricultura, índices de produtividade parcial do trabalho e da terra, assim como índices de produtividade total com base na teoria dos números-índices.

No entanto, a produtividade dos fatores pode estar sendo alterada ao longo dos anos pelo efeito escala e pela utilização da capacidade produtiva existente no setor agricola. A metodologia referida anteriormente não permite a desagregação desses efeitos e, portanto, acaba confundindo progresso técnico com produtividade total dos 
fatores. A metodologia a ser empregada no presente estudo permite decompor a taxa de crescimento da produtividade total dos fatores em progresso técnico, economias de escala e utilização da capacidade produtiva.

Arnade (1992) discute a modernização da agricultura brasileira no contexto do modelo de inovação induzida. O autor estimou uma função de custo generalizada de Leontief $e$, a partir dos coeficientes estimados, identificou as fontes de crescimento da produtividade total dos fatores. Os principais resultados referem-se a um crescimento da produtividade trabalho da ordem de 5,3\% a.a. de 2,8\% a.a. da produtividade da terra no periodo 1968 1987. O autor conclui, ainda, que o efeito escala é importante para a explicação do crescimento da produtividade total dos fatores, superando os efeitos provocados pela mudança técnica e eficiência.

Os trabalhos de Kwon (1986) e Braga \& Rossi (1988) utilizam esta metodologia para avaliar o desempenho da produtividade do setor industrial. Tal metodologia possibilita a decomposição dos efeitos que explicam o crescimento da produtividade total. O primeiro estudo focaliza o caso da Coréia do sul no período 1961-1980 e o segundo, o caso brasileiro, no período 1970-1983.

A decomposição da taxa de crescimento da produtividade, realizada por Braga e Rossi, indica que os rendimentos à escala e, em menor proporção, a utilização da capacidade produtiva influenciaram positivamente a evolução da taxa de produtividade. Já o deslocamento da função de custo, que estaria captando o efeito do progresso técnico e 
da melhoria das práticas gerenciais, surpreendentemente, aparece com sinal negativo em quase todos os tipos de indústria. Isto pode ser interpretado não apenas como ausência de progresso técnico, mas também como uma deterioração da eficiência produtiva da indústria. É possivel, entretanto, como sugeriram Denny, Fuss \& Wavernan, citados por Braga \& Rossi (1988), uma parcela da contribuição das economias de escala se deva, na verdade, à necessidade de ampliação da produção para permitir reduções de custo, incorporando inovações tecnológicas.

Estes resultados da decomposição da taxa de crescimento da produtividade dos fatores revelam um desempenho da indústria brasileira semelhante aos encontrados em países como Índia, México e Turquia, e são claramente inferiores aos apresentados em países desenvolvidos, como Estados Unidos, Japão e, mesmo, por alguns países em desenvolvimento do Sudeste Asiático.

A metodologia utilizada nestes estudos para analisar a produtividade total da indústria será, então, adaptada para o caso da agricultura brasileira. Por isso mesmo, apresenta-se, no capítulo 4, a metodologia para a obtenção dos efeitos do progresso técnico, dos ganhos de escala e de utilização da capacidade produtiva na agricultura. 


\section{REFERENCIAL TEÓRICO}

A literatura sobre medidas de crescimento da produtividade é baseada, principalmente, em modelos que incorporam pressuposições muito restritivas, como a de retornos constantes à escala. Recentemente, diversos pesquisadores têm levado em conta outras características relevantes do processo de produção, de tal forma que se possa isolar o "verdadeiro" crescimento da produtividade. A importância dos retornos à escala sobre a medida do crescimento da produtividade, particularmente do lado dos custos, foi salientada por Ohta (1975) e elaborada por Morrison (1986), Fuss \& Waverman (1986), dentre outros.

O desempenho da produtividade é determinado pelo aumento da eficiência ao longo do tempo. Refere-se, portanto, ao crescimento da produtividade total. Esta noção pode ser formalizada através de duas formas alternativas, o crescimento no produto mantendo os insumos constantes, ou a diminuição dos custos, dados os níveis de produto e preços dos insumos. 


\subsection{Análise através da função de produção}

Assim sendo, assuma que uma firma tenha a seguinte função de produção $Q=f(X, T)$, ou equivalentemente, a função de custo dual $C=g\left(P_{i}, Q, T\right)$ onde $X$ é o vetor de $i$ insumos, $\mathrm{P}_{\mathrm{i}}$ é o vetor de preços desses insumos, $e^{\mathrm{T}}$ representa a tecnologia (geralmente medida por uma tendência). A medida de crescimento da produtividade total é formalizada usando-se as elasticidades das funções acima com relação a $T$ : especificamente, $\frac{\partial \ln Q}{\partial \mathrm{T}}=\varepsilon q t$ e $\frac{\partial \ln C}{\partial T}=\varepsilon C t$. Essas expressões refletem os resíduos do crescimento da produção total (ou do custo) menos as contribuições das variáveis das funções. Com a pressuposição de ajustamento instantâneo, retornos constantes à escala e competição perfeita, este resíduo isola a mudança técnica (Solow, 1958).

A elasticidade $\varepsilon q t$ representa o potencial de aumento no produto entre dois períodos de tempo para uma dada quantidade de insumos. O cálculo desse resíduo pode ser feito da seguinte forma (Morrison, 1992):

Diferenciando totalmente Q em relação a T, em logaritmo, obtém-se:

$$
\frac{d \ln Q}{d T}=\frac{\partial \ln Q}{\partial \ln X_{i}} \times \frac{d \ln X_{i}}{d T}+\frac{\partial \ln Q}{\partial T}
$$




$$
\begin{aligned}
& \frac{d \ln Q}{d T}=\frac{\Delta Q}{Q}, \\
& \frac{d \ln X}{d T}=\frac{\Delta X_{i}}{X_{i}} e \\
& \frac{\partial \ln Q}{\partial \ln X_{i}}=\frac{\partial Q}{\partial X_{i}} \times \frac{X_{i}}{Q}
\end{aligned}
$$

Substituindo esses valores na expressão da diferencial total, e generalizando para i insumos, tem-se:

$$
\frac{d \ln Q}{d T}-\frac{d \ln X}{d T}=\frac{\Delta Q}{Q}-\sum_{i} s_{i}\left(\Delta X_{i} / X_{i}\right)=\varepsilon q t
$$

onde $s_{i}$ é "factor share" do insumo i em termos do valor do produto total $\left(\mathrm{P}_{\mathrm{i}} \mathrm{X}_{\mathrm{i}} / \mathrm{P}_{Q} \mathrm{Q}\right)$. Esta igualdade é obtida tomando-se a diferencial da função de produção:

$$
\frac{d \ln Q}{d T}=\left(\frac{1}{Q}\right)\left(\frac{\partial Q}{\partial T}+\sum_{i}\left(\partial Q / \partial x_{i}\right)\left(d X_{i} / d T\right)\right)
$$

reconhecendo que, com a maximização de lucro e concorrência perfeita,

$$
\mathrm{P}_{\mathrm{Q}}\left(\partial \mathrm{Q} / \partial \mathrm{X}_{\mathrm{i}}\right)=\mathrm{P}_{\mathrm{i}}
$$

Assim, o progresso tecnológico, expresso por $\frac{d \ln Q}{d T}$, representa o aumento ocorrido na produção que não é explicado pelo aumento no uso dos insumos. Mais especificamente, a taxa de crescimento do produto possui dois componentes: um baseado na taxa de crescimento do uso dos insumos e outro que é o componente residual representando o progresso técnico. O aumento da producão em 
decorrência do incremento no uso dos insumos representa um movimento ao longo da função de produção, enquanto o progresso tecnológico, medido de forma residual, representaria um deslocamento da função de produção (Solow, 1958 ).

\subsection{Análise através da função de custo}

Similarmente à análise usando a função de produção, o crescimento da produtividade, a partir da função custo, pode ser medido como:

$\left(a \ln c / d T-a \ln P_{i} / d T\right)=(\Delta c / C)-\sum M_{i}\left(\Delta P_{i} / P_{i}\right)=\partial \ln c / \partial T=\varepsilon c t$

onde c é o custo total unitário $\left(C(P, T)=C(P, T, Q) / Q\right.$ com retornos constantes à escala), e $M_{i}$ é "factor share" do insumo i no custo, ou seja, $\left(\mathrm{X}_{\mathrm{i}} \mathrm{P}_{\mathrm{i}} / \mathrm{C}\right)$. Esta igualdade é baseada na manipulação da derivada da função de custo unitário:

$$
\begin{aligned}
& d c / d T=\partial c / \partial T+\sum_{i} \partial c / \partial P_{i}\left(d P_{i} / d T\right), \\
& \text { assim, como feito na função de produção }
\end{aligned}
$$

$Q(X, T)$.

A importância de entender a análise convencional, em situações onde existam efeitos de economias de escala, foi reconhecida por ohta (1975). Retornos para a firma devido a economias de escala causam uma mudança no custo marginal ( $\mathrm{CM}=\mathrm{dCT} / \mathrm{dQ})$ e no custo médio 
$(\mathrm{CMe}=\mathrm{C} / \mathrm{Q})$. Desta forma, surge uma diferença entre $\mathrm{P}_{Q} \mathrm{e}$ CM. Intuitivamente, os ganhos adivindos de economias de escala poderiam não estar relacionados com a mudança técnica, mas às características tecnológicas do processo que possibilitam às firmas maior eficiência com níveis de produção mais altos, independentemente da mudança técnica.

A medida do crescimento da produtividade total dos fatores (PTF) pode ser decomposta em progresso tecnológico, economias de escala e utilização da capacidade de produção.

A taxa de crescimento da PTF é definida como $P T F=\dot{Q}-\dot{X}$ e mede a mudança ocorrida no produto (Q) que não é explicada pelo uso dos insumos (X).

Sobre a pressuposição de minimização de custo, a teoria da dualidade diz que, para qualquer função de produção, existe uma função de custo que fornece uma descrição equivalente da tecnologia (Know, 1986).

Considere, portanto, a seguinte função de custo:

$$
C=g\left(P_{i}, Q, T, \lambda\right)
$$

onde:

$P_{i}=$ vetor dos preços dos insumos;

$Q=$ nível de produção;

$T=$ tempo (indicador do progresso técnico);

e, 
$\lambda=$ taxa de utilização da capacidade produtiva.

A diferencial total de (01) com relação a T é:

$$
\frac{d C}{d T}=\sum_{i=1}^{n} \frac{\partial g}{\partial P_{i}} \times \frac{d P_{1}}{d T}+\frac{\partial g}{\partial Q} \times \frac{d Q}{d T}+\frac{\partial g}{\partial T} \times \frac{d T}{d T}+\frac{\partial g}{\partial \lambda} \times \frac{d \lambda}{d T}
$$

Dividindo a expressão (02) por C, fazendo $\partial g / \partial p_{i}=x_{i}$ (lema de Shephard), onde $x_{i}$ é a quantidade do insumo $i$, e multiplicando e dividindo a $1 \%$ a $2 \cong$ e a 4 parcelas do segundo membro por $P_{i}, Q$ e $\lambda$, tem-se:

$$
\dot{C}=\sum_{i=1}^{n} \frac{P_{i} X_{i}}{C} \times \stackrel{\circ}{P_{i}}+\frac{\partial g}{\partial Q} \times \frac{Q}{C} \times \dot{Q}+\frac{1}{C} \times \frac{\partial g}{\partial T}+\frac{\partial g}{\partial \lambda} \times \frac{\lambda}{C} \times \ddot{\lambda}
$$

Onde o ponto sobre a variável significa a taxa de crescimento percentual.

Define-se, agora, $\stackrel{\circ}{\beta}=\frac{\partial g}{\partial T} \times \frac{1}{C}$ como sendo o deslocamento da função de custo devido ao progresso técnico. Sejam, ainda, as elasticidades de custo em relação ao produto $\left(\varepsilon_{\mathrm{cq}}\right)$ e à utilização da capacidade produtiva $\left(\varepsilon_{c \lambda}\right)$, respectivamente, representadas por:

$$
\varepsilon_{c Q}=\frac{\partial g}{\partial Q} \times \frac{Q}{C} \quad \text { e } \quad \varepsilon_{C \lambda}=\frac{\partial g}{\partial \lambda} \times \frac{\lambda}{C}
$$

Substituindo essas expressões em (3), temse:

$$
\stackrel{\circ}{\beta}=C^{\circ}-\sum_{i} \frac{P_{i} X_{i}}{C} \dot{\circ}_{i}-\varepsilon_{c Q} \stackrel{\circ}{Q}-\varepsilon_{c \lambda} \dot{\lambda}
$$


Tomando a diferencial total de $\mathrm{C}=\sum \mathrm{P}_{\mathrm{i}} \mathrm{X}_{\mathrm{i}} \mathrm{em}$ relação ao tempo e reagrupando os termos de expressão, obtém-se:

$$
\sum_{i} \frac{P_{i} X_{i}}{C} \dot{P}_{i}=\dot{C}-\sum_{i} \frac{P_{i} X_{i}}{C} \dot{X}_{i}
$$

e, considerando que a taxa de crescimento do

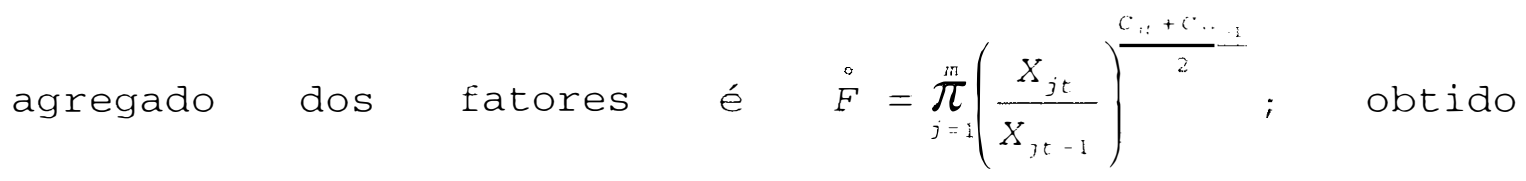
utilizando denominador do indice de Tornqvist/ver apêndice 1 ).

Substituindo (5) em (04), tem-se:

$$
-\ddot{\beta}=\varepsilon_{c Q} \dot{Q}+\varepsilon_{c \dot{\lambda}} \dot{\lambda}-\ddot{F}
$$

Uma vez que a PiTF $=\stackrel{Q}{-}-\dot{F}$, obtêm-se, finalmente:

$$
\stackrel{\circ}{P T F}=-\dot{\beta}+\left(1-\varepsilon_{c Q}\right) \stackrel{\circ}{Q}-\varepsilon_{c \lambda} \dot{\lambda}
$$

Esta expressão mostra que se os rendimentos à escala forem constantes $\left(\varepsilon_{\mathrm{cq}}=1\right)$ e a elasticidade do custo com respeito à utilização da capacidade $\left(\varepsilon_{c \lambda}\right)$ for

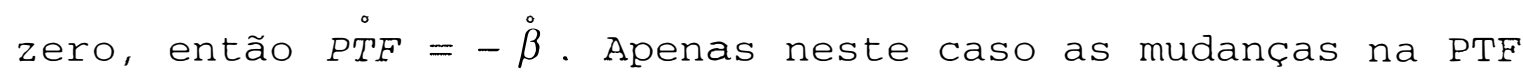
refletirão mudanças nas respectivas funções de produção e de custo. Para separar os efeitos supracitados basta estimar as elasticidades correspondentes. 


\section{METODOLOGIA}

Em sua primeira parte, este capitulo objetiva descrever o método utilizado para estimar as elasticidades relevantes, a partir de uma função custo translog. Em seguida, são apresentadas as definições das variáveis consideradas.

\subsection{Estimativa das elasticidades relevantes: a função custo translog}

Diversas vantagens podem ser enumeradas para a utilização da função custo para a determinação dos parâmetros de produção em lugar da função de produção (Binswanger, 1974). Primeiramente, as funções de custo são homogêneas em preços, independentemente das propriedade de homogeneidade da função de produção, já que a duplicação de todos os preços pode implicar a duplicação dos custos, sem influenciar as razões de quantidade dos fatores. Segundo, as funções de custo incluem preços, que são variáveis exógenas no processo decisório do empresário individual, e não quantidades de fatores, cujos níveis de uso são decisões endógenas no processo de decisão. Terceiro, na 
estimação das funções de custo, geralmente, não ocorrem problemas sérios de multicolinearidade, tendo em vista que as correlações entre os preços são baixas.

O modelo econométrico utilizado nesta pesquisa é a função custo translog, por apresentar as vantagens referidas anteriormente e maior flexibilidade na estimativa dos parâmetros a serem estimados, bem como maior coerência com os conceitos econômicos apresentados no capítulo 3. Diferentemente das tradicionais funções CobbDouglas e CES, a função translog não impõe qualquer restrição aos valores das elasticidades de substituição nem pressupõe homogeneidade da função.

Varian (1984), Beattie \& Taylor (1985), Binswanger (1974), Dias (1982) e Albuquerque (1987) apresentam a teoria do custo e discutem a função custo translog com riqueza de detalhes.

Para a estimação das elasticidades $\varepsilon_{C Q}$ e

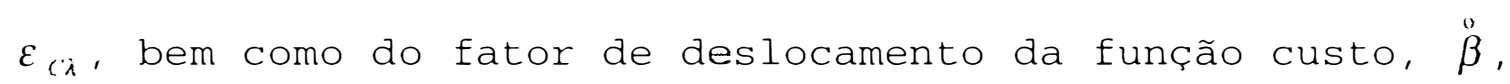
adota-se a seguinte especificação para a função custo translog:

$$
\begin{aligned}
\ln C & =\alpha_{0}+\sum_{i} \alpha_{i} \ln P_{i}+1 / 2 \sum_{i} \sum_{j} \gamma_{i j} \ln P_{i} \ln P_{j}+a_{0} \ln Q+\frac{1}{2} a_{l Q Q}(\ln Q)^{2}+ \\
& +\sum_{i} \sigma_{Q i} \ln Q \ln P_{i}+\sum_{i} \theta_{i} \ln P_{i} \ln t+\sum_{i} \delta_{i} \ln P_{i} \ln \lambda+\beta_{t} \ln t+\frac{1}{2} \beta_{t}(\ln t)^{2}+ \\
& +\theta_{Q} \ln Q \ln t+\delta_{Q} \ln Q \ln \lambda+\delta_{t} \ln \lambda \ln t+\rho_{\lambda} \ln \lambda+\frac{1}{2} \rho_{\lambda \lambda}(\ln \lambda)^{2}+v
\end{aligned}
$$


onde, C é o custo total de produção;

Q é o produto total da agropecuária;

$\mathrm{P}$ é o preço dos insumos terra, trabalho e

capital;

$\lambda$ é o indice de capacidade produtiva do setor agrícola; e,

t é a variável tendência.

Utilizando o lema de Shephard, as equações das participações dos insumos nos custos $\left(S_{i}\right)$ podem ser expressas por:

$\frac{\delta \ln C}{\delta \ln P_{i}}=\frac{P_{i} X_{i}}{C}=S_{i}=\alpha_{i}+\frac{1}{2} \sum_{i} \gamma_{i j} \ln P_{j}+\sigma_{\theta i} \ln Q+\theta_{i} \ln t+\delta_{i} \ln \lambda+v_{i}$

Para que a função custo translog satisfaça as propriedades neoclássicas da teoria da produção, as seguintes restrições devem ser impostas aos seus parâmetros:

$$
\begin{aligned}
& \sum_{i} \alpha_{i}=1 \\
& \text { e } \\
& \sum_{i} \gamma_{i j}=\sum_{i} \theta_{i}=\sum_{i} \delta_{i}=\sum_{i} \sigma_{Q i}=0
\end{aligned}
$$

Isto significa que a função custo é linearmente homogênea nos preços dos insumos. Impondo, ainda, a usual restrição de simetria, $\gamma_{i j}=\gamma_{j i}$, chega-se a

$$
\sum_{i} \gamma_{i j}=\sum_{j} \gamma_{i j}
$$


Com essas restrições, tem-se uma redução do número de parâmetros a serem estimados.

As elasticidades $\varepsilon_{C Q}$ e $\varepsilon_{C \lambda}$, podem, então, ser calculadas a partir dos seguintes estimadores da função custo translog:

$$
\begin{gathered}
\varepsilon_{C Q}=a_{Q}+a_{Q Q} \ln Q+\sum_{i} \sigma_{Q i} \ln P_{i}+\theta_{Q} \ln t+\delta_{Q} \ln \lambda \\
e \\
\varepsilon_{i \cdot \lambda}=\rho_{\lambda}+\rho_{\lambda \lambda} \ln \lambda+\sum_{i} \delta_{i} \ln P_{i}+\delta_{Q} \ln Q+\delta_{i} \ln t
\end{gathered}
$$

O fator de deslocamento da função de custo, ק, pode também ser obtido de modo análogo, isto é, $\dot{\beta}=\partial \ln C / \partial \ln t^{.}$

O sistema composto pelas equações (08) e (09) é estimado pelo método de zellner para regressões aparentemente não-relacionadas, uma vez que os resíduos dessas equações são correlacionados. Esse método consiste na aplicação de mínimos quadrados generalizados (MQG), ponderados pelạ matriz de correlação dos resíduos, obtidos da estimação de cada equação por mínimos quadrados simples (MQS) .

O método será aplicado iterativamente para garantir que os estimadores sejam de máxima verossimilhança. Kmenta e Gilbert, citados por Braga \& Rossi (1998), demonstram que, havendo convergência na 
estimação interativa do método de zellner, obtêm-se estimadores de máxima verossimilhança.

\subsection{Definição das Variáveis}

Foram utilizadas informações relativas aos preços da terra, da mão de obra e de máquinas, e suas respectivas participações no custo; um índice de quantidade de produto; um índice de capacidade; e, o custo. Duas séries de dados de preços, participações e custo foram concatenadas: a de Santos (1986) e a de Gasques e Conceição (1997).

A construção das variáveis relativas aos preços dos fatores, no período 1955-1974, foi obtida da série disponível para o Brasil, apresentada por Santos (1986). Neste trabalho, como "proxy" do preço da terra $\left(P_{t}\right)$ considerou-se o preço médio do arrendamento; para o da mãode-obra $\left(\mathrm{P}_{\mathrm{L}}\right)$, o salário do trabalhador diarista, ambos obtidos da série de preços de fatores publicados pelo Centro de Estudos Agrícolas da Fundação Getúlio Vargas. Para obter o preço dos serviços das máquinas $\left(\mathrm{P}_{\mathrm{m}}\right)$ foram considerados: valor de mercado das máquinas, expectativa de vida útil (10 anos) e uma taxa de desconto $(0,06)$.

Segundo Santos (1986), o valor anual dos serviços da terra foi obtido multiplicando-se a área total explorada pelo preço médio de arrendamento; o valor anual dos serviços de mão-de-obra, multiplicando-se o número de 
trabalhadores pelo preço da mão-de-obra, e o valor anual dos serviços de máquinas, multiplicando-se o preço do serviços de máquinas pelo estoque físico de máquinas existente em 1950, agregando-se, anualmente, os tratores vendidos no mercado interno.

A soma desses valores constitui o custo anual (C), especificado no modelo e a base de referência para obtenção das participações dos fatores. Os dados apresentados por Santos foram atualizados monetariamente para Cr\$ de 1985, utilizando-se o IGP-DI da FGV.

Com essas informações, foram obtidas as participações da terra $\left(S_{t}\right)$, da mão-de-obra $\left(S_{L}\right)$ e de máquinas $\left(S_{M}\right)$ no custo total.

Para o período 1975-1994, foram utilizados dados publicados pela Fundação Instituto Brasileiro de Geografia e Estatística (IBGE), pela Associação Nacional dos Fabricantes dos Veículos Automotores (ANFAVEA) e pelo Centro de Estudos Agrícolas da Fundação Getúlio Vargas (FGV). Como dito anteriormente, esse conjunto de estatísticas foi elaborado por Gasques \& Conceição (1997).

O preço médio de arrendamento para lavouras, publicado pela FGV, foi utilizado como "proxy" do preço do fator terra. O valor anual dos serviços da terra foi obtido pela multiplicação deste preço pela área de lavouras permanentes e temporárias, obtida da Pesquisa Agrícola Municipal (PAM) do IBGE. Seria importante, também, levar em conta as áreas de pastagem, mas elas não são disponíveis.

O preço do fator trabalho foi obtido dos relatórios da Pesquisa Nacional por Amostra de Domicílios 
(PNAD), sobre pessoal ocupado e seus rendimentos, segundo ramos de atividades. O ponto médio de cada classe de rendimento, definido na PNAD, é uma estimativa do preço do fator. Para estimar o valor anual dos serviços do fator trabalho, multiplicou-se o rendimento médio de cada classe pelo número de pessoas ocupadas.

O preço do fator capital foi obtido dos relatórios publicados pela ANFAVEA, dividindo-se o faturamento da indústria pela quantidade de máquinas e peças vendidas. O valor anual dos serviços do fator capital foi estimado acumulando-se ao estoque do ano anterior a quantidade de máquinas vendidas, multiplicado pelo "preço médio" das máquinas e peças, admitindo-se uma taxa linear de depreciação igual a 0,10. É de se observar que - face à indisponibilidade de dados anuais sobre outros itens do capital agrário - a mensuração do seu valor está subestimada.

A soma desses fluxos determina o custo total (C) utilizado para a obtenção das participações dos fatores (factor share). A exemplo do procedimento utilizado para a série de Santos; 1955-1974, todos os valores foram corrigidos monetariamente para Cr\$1985, utilizando-se o IGP-DI da FGV.

A obtenção de um indicador para mensuração da taxa de utilização da capacidade ( $\left.I_{C}\right)$ na agricultura teve por base as áreas com culturas permanentes e temporárias, pastagens naturais e plantadas e matas plantadas, publicadas no Censo Agropecuário de 1985, por ser a última informação censitária disponível para o 
Brasil. Face a indisponibilidade de dados anuais sobre pastagem, ao se calcular a variação percentual da área explorada em cada ano, dividiu-se a área correspondente à lavouras temporárias e permanentes pela área total explorada em 1985. Em seguida, determinou-se o índice de utilização da capacidade tendo como base a "área-base" de 1985 .

O indicador de quantidade $\left(I_{Q}\right)$ foi obtido pela agregação das culturas temporárias, permanentes e também da produção animal. A partir das informações de quantidade e valor da produção, obtidos junto ao IBGE, na Pesquisa Agrícola Municipal e na Pesquisa Pecuária Municipal, foi construído o indicador com base no numerador do índice de Tornqvist(Apêndice 1). Foram utilizados dados de aproximadamente 70 culturas, além de informações relativas ao abate de animais, produção de leite, ovos, mel e casulo.

A construção de uma série longa de dados sempre constitui uma tarefa de relativa dificuldade. Várias são as complicações enfrentadas, tais como: falta de informações, mudanças na metodologia de obtenção de dados e irregularidade temporal no levantamento de estatísticas básicas (caso dos últimos censos). Estes problemas podem subestimar algumas variáveis, mas, como estas foram tratadas uniformemente na construção das séries, é de se esperar que problemas sejam parcialmente amenizados. 


\section{ANÁLISE DOS RESULTADOS}

A estimação da função de custo translog foi feita com base nas informações de preço da terra $\left(P_{t}\right)$, de mão-de-obra $\left(\mathrm{P}_{\mathrm{L}}\right)$ e de máquinas $\left(\mathrm{P}_{\mathrm{M}}\right)$; de um índice de quantidade $\left(I_{Q}\right)$, um indicador de utilização da capacidade $\left(I_{C}\right)$ e estimativas das participações dos fatores terra ( $S_{T}$ ) trabalho $\left(S_{\mathrm{L}}\right)$ e capital $\left(S_{M}\right)$ no custo total. Estas informações são apresentadas no apêndice 2 .

O sistema composto por uma equação de custo e duas equações de participação foi estimado pelo método de Zellner (1962), para regressões aparentemente nãorelacionadas (Seemingly Unrelated Regression), uma vez que os resíduos dessas equações são correlacionados. Este método consiste. na aplicação de mínimos quadrados generalizados (MQG), ponderados pela matriz de correlação dos resíduos, obtidos da estimação de cada equação por mínimos quadrados simples (MQS). Para maiores detalhes ver Greene (1997) .

o método foi aplicado iterativamente, ocorrendo convergência na estimação do modelo, obtendo-se, desta forma, estimadores de máxima verossimilhança. O método exige que uma das três equações de parcela (participação) de custo seja eliminada do sistema, a fim de 
se obter não-singularidade na matriz de variânciacovariância dos termos do erro. Tendo em vista que o método de zellner é invariante em relação à equação omitida, preferiu-se excluir a equação de parcela de máquinas, pelas dificuldades encontradas na mensuração do fator capital.

Como os parâmetros das equações de participação são um sub-conjunto dos parâmetros da função custo, ao se estimar conjuntamente a função custo e as equações de participação aumentam os graus de liberdade, o que é particularmente relevante no presente estudo.

Vale ressaltar que, considerando as restrições paramétricas de que a função custo deve ser linearmente homogênea nos preços dos fatores, foram inseridas no modelo as seguintes restrições: $\sum_{i} \alpha_{1}=1$ e $\sum_{i} \gamma_{i j}=\sum_{i} \theta_{1}=\sum_{i} \delta_{1}=\sum_{i} \sigma_{\varrho_{l}}=0 \quad$ e $\quad \sum_{i} \gamma_{i j}=\sum_{i} \gamma_{i j}$. Assim sendo, estimou-se o modelo restrito.

Foram estimadas 3 especificações para a função custo translog. Inicialmente, incluiu-se uma variável dummy para verificar se havia diferença entre as séries 1955-1974 e 1975-1994, uma vez que estas foram concatenadas nesta pesquisa. Como a variável dummy não foi significativa, o que demonstra coerência na elaboração da série, estimou-se novo modelo sem a inclusão desta variável. Como o termo constante não foi significativo ao nível de 10\%, estimou-se um terceiro modelo, sem a constante e sem a variável dummy. Os parâmetros estimados, com os respectivos erros-padrões, são apresentados no Apêndice 3. Foi analisado o modelo estimado com constante. 
A partir da estimativa dos parâmetros da função custo foi possível calcular a produtividade da agricultura brasileira no período 1955-1994. Numa tentativa de melhor observar a evolução dos fatores determinantes da PTF, este período de análise foi subdivido em dois grandes intervalos. O primeiro, 1955-1975, compreendendo a fase precursora do processo de modernização da agricultura, quando foram implementadas as principais medidas de políticas visando sua transformação. Os grandes problemas da agricultura foram discutidos nesta fase, coincidindo com - período de implementação do planejamento no Brasil, a partir da formulação de planos de desenvolvimento como o Plano de Metas, o Plano Trienal, o PAEG e o I PND. O papel da agricultura começa então a ser evidenciado e melhor considerado pelos "policy makers".

O segundo período, 1975-1994, caracteriza-se pela necessidade de promoção de um ajuste no processo de desenvolvimento econômico. As questões relacionadas com os reflexos das crises do petróleo (1973 e 1979), a crise da dívida externa (1982), os planos de estabilização econômica e a redefinição do papel do Estado produziram impactos diferenciados nos diversos setores produtivos. Tais ajustes determinaram mudanças na condução das políticas voltadas para a agricultura, principalmente durante a década de 80. Modernização da produção, ganhos de produtividade e competitividade começam a ser perseguidos. Para especificar melhor este momento de ajuste, foram geradas e analisadas informações específicas para o sub-período 1980-1994.

A seguir, é analisado o comportamento da agricultura no que se refere à produtividade total dos 
fatores (PTF). A Tabela 1 apresenta as elasticidades-custo em relação à produção $\left(\varepsilon_{c Q}\right)$ e à utilização de capacidade $\left(\varepsilon_{(\lambda)}\right)$, bem como a estimativa do parâmetro de retornos à escala $\left(1-\varepsilon_{C Q}\right)$. Todos eles obtidos a partir da utilização dos parâmetros da função de custo.

Tabela 1. Estimativa da elasticidade-custo em relação à produção, à utilização da capacidade e dos retornos à escala. Valores médios do período 1955-1994.

\begin{tabular}{cccc}
\hline & \multicolumn{2}{c}{ Elasticidade-Custo } & \\
\cline { 2 - 3 } Período & Produção & $\begin{array}{c}\text { Utilização da } \\
\text { Capacidade }\end{array}$ & $\begin{array}{c}\text { Retornos à } \\
\text { Escala } \\
\left(1-\varepsilon_{C Q}\right)\end{array}$ \\
\hline $1955-1975$ & 0,48311 & $\varepsilon_{(\lambda)}$ & 0,51689 \\
$1975-1994$ & 0,49649 & $-0,31878$ & 0,53894 \\
$1980-1994$ & 0,49951 & $-0,34553$ & 0,50049 \\
$1955-1994$ & 0,48971 & $-0,32923$ & 0,51029 \\
\hline
\end{tabular}

Fonte: Dados da pesquisa

Observa-se, no período 1955-1994, que as estimativas para $\varepsilon_{C Q}$ e para $\left(1-\varepsilon_{C Q}\right)$ evidenciam expressivos retornos positivos à escala, o que indica um aumento no custo proporcionalmente inferior ao crescimento da produção. Quanto à elasticidade $\varepsilon_{C \lambda}$, constata-se o comportamento esperado, isto é, ocorre uma redução do custo a partir da maior utilização da capacidade. O efeito da utilização da capacidade sobre o custo total é ligeiramente superior no período 1980-1994. 
A decomposição do indicador de produtividade total possibilita $\circ$ melhor entendimento de seu comportamento ao longo do tempo, em função de três fatores: deslocamento dà função custo (mudança técnica), retornos à escala e utilização da capacidade.

A Tabela 2 apresenta a estimativa da taxa de crescimento da produtividade total dos fatores (PTF) e sua decomposição. A taxa de variação da produtividade é positiva no período 1955-1994; próxima a 1\% a.a.. Taxas muito superiores, de aproximadamente 2,0\% a.a., são estimadas para os períodos de 1975-1994 e 1980-1994. Fato interessante refere-se à taxa negativa de produtividade total (-1,2\% a.a.) no período 1955-1975, quando os efeitos das políticas voltadas para a transformação da agricultura (crédito rural, por exemplo) não foram suficientes para anular/compensar a falta de progresso técnico.

Tabela 2. Produtividade total dos fatores na agricultura brasileira e sua decomposição. Valores médios do período 1955-1994.

\begin{tabular}{|c|c|c|c|c|}
\hline Período & $\begin{array}{c}\text { Produtividade } \\
\text { Total dos } \\
\text { Fatores }\end{array}$ & $\begin{array}{l}\text { Mudanças da } \\
\text { Função de } \\
\text { Custo }\end{array}$ & $\begin{array}{c}\text { Retornos à } \\
\text { Escala }\end{array}$ & $\begin{array}{c}\text { Capacidade } \\
\text { de } \\
\text { Utilização }\end{array}$ \\
\hline & $\dot{P} \dot{T}^{a}$ & $-\dot{\beta}$ & $\left(1-\varepsilon_{c u}\right) \dot{Q}$ & $-\varepsilon_{C \lambda} \dot{\lambda}$ \\
\hline $1955-1975$ & $-0,011949$ & $-0,036475$ & 0,013347 & 0,011179 \\
\hline $1975-1994$ & 0,019725 & 0,001511 & 0,014013 & 0,004201 \\
\hline $1980-1994$ & 0,020942 & 0,007167 & 0,011625 & 0,002149 \\
\hline $1955-1994$ & 0,008095 & $-0,012739$ & 0,013234 & 0,007601 \\
\hline
\end{tabular}

Fonte: Dados da pesquisa

Nota: a: $\operatorname{TPF}=-\ddot{\beta}+\left(1-\varepsilon_{\mathrm{CQ}}\right) Q-\varepsilon_{\mathrm{c} \lambda} \ddot{\lambda}$ 
O deslocamento da função custo $(-\dot{\beta})$ registra contribuição negativa para o crescimento da PTF no período 1955-1994. Em princípio, este resultado sugere que o efeito isolado do progresso técnico não foi positivo no período em estudo. No entanto, exame mais preciso dos períodos 19751994 e 1980-1994, quando ocorreu - de fato - mudança técnica, demonstra que aquele resultado (negativo) foi influenciado pela magnitude de $(-\dot{\beta})$ observada no período inicial (1955-1975).

Corroborando a interpretação acima, deslocamento da função de custo total, no período $1975-$ 1994, responde por 7,7\% do crescimento da PTF. Tal contribuição cresce para 34,22\% no período 1980-1994.

Como a estimativa dos ganhos de eficiência com a mudança técnica é obtida residualmente, sua interpretação pode, eventualmente, incluir erros resultantes da estimação das elasticidades custo/produção $\left(\varepsilon_{(\varrho)}\right)$ e custo/utilização do capital ( $\left.\varepsilon_{C \lambda}\right)$.

No período 1975-1994, os retornos à escala (1.4\%a.a.) respondem por 71\% do crescimento da produtividade total dos fatores e a utilização da capacidade $(0,4 \%$ a.a.) por 21,3\% da evolução da PTF. Este resultado é importante para o entendimento do desempenho da agricultura e os reflexos provocados. A importância dos retornos à escala foi também evidenciada por Arnade (1992) no período 1968-1987.

Modo adicional para investigar o que explica - processo de modernização, consiste na observação das taxas de crescimento da produção e dos insumos (Tabela 3 ). 
Durante o período 1955-1994, a taxa de crescimento da produção foi de $2,59 \%$ a.a., superior portanto à taxa do total de insumos $(1,78 \%$ a.a.).

Tabela 3. Taxa média de crescimento da utilização de insumos, da quantidade de produto e da capacidade de utilização na agricultura brasileira. Período $1955-1994$.

\begin{tabular}{|c|c|c|c|c|c|c|}
\hline \multirow{3}{*}{ Período } & \multirow{2}{*}{$\begin{array}{l}\text { Total dos } \\
\text { Fatores }\end{array}$} & \multicolumn{3}{|c|}{ Fatores } & \multirow{2}{*}{$\begin{array}{l}\text { Indice de } \\
\text { Quantidade }\end{array}$} & \multirow{2}{*}{$\begin{array}{c}\text { Capacidade de } \\
\text { Utilização }\end{array}$} \\
\hline & & Máquinas & Terra & Trabalho & & \\
\hline & $\dot{F}$ & $\dot{M}$ & $\dot{T}$ & $i$ & $\dot{Q}$ & $\dot{\lambda}$ \\
\hline $1955-1975$ & 0,037771 & 0,105803 & 0,035069 & 0,048124 & 0,025822 & 0,035069 \\
\hline $1975-1994$ & 0,008105 & 0,031246 & 0,012394 & 0,009023 & 0,027830 & 0,012394 \\
\hline $1980-1994$ & 0,002286 & $-0,000693$ & 0,006220 & 0,002242 & 0,023228 & 0,006220 \\
\hline $1955-1994$ & 0,017839 & 0,065660 & 0,023086 & 0,018076 & 0,025934 & 0,023086 \\
\hline
\end{tabular}

Fonte: Dados da pesquisa

Entre os insumos, a maior taxa de crescimento anual, no período de 1955-1994, foi apresentada pelo capital na forma de máquinas $(6,6 \%)$, seguida pelas taxas de crescimento do uso de terra $(2,3 \%)$ e trabalho $(1,8 \%)$.

A análise dos períodos 1955-1975, 1975-1994 e 1980-1994 demonstra que os fatores apresentam taxas de crescimento em declínio, inclusive a capacidade de utilização. Por outro lado, a taxa de crescimento do produto agropecuário oscila em torno de 2,5\% ao ano.

Do lado dos custos, no período 1955-1994, terra e trabalho são responsáveis, em média, por 49,9\% e 50,1\%, respectivamente. O componente máquinas tem 
participação apenas residual. Foi observada, porém, uma alteração na importância das parcelas dos fatores convencionais (terra e trabalho) no custo total, tomando por base o período 1955-1975. Neste, o trabalho responde por cerca de 70\% do custo, enquanto no período 1975-1994, a participação da terra (72\%) torna-se a principal parcela do custo total (Apêndice 2).

A análise da contribuição da produtividade total dos fatores para o crescimento da produção agropecuária é realizada a partir dos dados da Tabela 4.

Tabela 4. Fontes de crescimento da produção da agricultura brasileira. Valores médios do período 1955-1994

\begin{tabular}{|c|c|c|c|c|c|}
\hline \multirow[b]{2}{*}{ Período } & \multirow{2}{*}{$\begin{array}{c}\text { Índice de } \\
\text { Quantidade } \\
\dot{L}\end{array}$} & \multicolumn{4}{|c|}{$\begin{array}{l}\text { Importância Relativa das Fontes } \\
\text { Crescimento da Produção (em \%) }\end{array}$} \\
\hline & & $\begin{array}{l}\text { Produtividade } \\
\text { PंF }\end{array}$ & $\begin{array}{l}\text { Mácquina } \\
\dot{M}\end{array}$ & $\begin{array}{l}\text { Terra } \\
\dot{T}\end{array}$ & $\begin{array}{c}\text { Trabalho } \\
i\end{array}$ \\
\hline $1955-1975$ & 0,025822 & $-46,28$ & 0,060 & 35,39 & 110,83 \\
\hline $1975-1994$ & 0,027830 & 70,88 & 0,083 & 22,67 & 6,37 \\
\hline $1980-1994$ & 0,023228 & 90,16 & 0,001 & 12,62 & $-2,78$ \\
\hline $1955-1994$ & 0,025934 & 31,21 & 0,067 & 28,42 & 40,30 \\
\hline
\end{tabular}

Fonte: Dados da pesquisa

No período 1955-1994, a produtividade dos fatores contribui positivamente para o crescimento da produção, com cerca de 31\%. Esta contribuição não é, entretanto, homogênea no tempo. No período 1955-1975, a PTF afeta negativamente o crescimento do produto, o que foi fortemente compensado pela participação positiva do fator trabalho. 
Este resultado subsidia e fortalece o debate sobre a ausência de ganhos de produtividade que caracterizava a agricultura brasileira até meados da década de 70. O esforço realizado, a partir de políticas específicas para o setor, como a de crédito rural, comercialização e, em especial, de pesquisa e extensão rural, muito contribuiu para a importância que a produtividade total dos fatores tem, hoje, na explicação do crescimento do produto. No período 1980-1994, por exemplo, a PTF chega a se responsabilizar por $90 \%$ do crescimento da produção agropecuária. Possivelmente, boa parte desta elevada contribuição da PTF pode ser atribuída aos investimentos realizados, a partir de 1973, em pesquisa agrícola. 


\section{CONCLUSÕES}

Os resultados deste estudo permitem avaliar a evolução da produtividade da agricultura no período 19551994. Para tanto, foi utilizado o conceito de produtividade total dos fatores que reflete, mais adequadamente, a eficiência com que a agricultura transforma insumos em produtos. A metodologia empregada possibilita, adicionalmente, decompor a taxa de crescimento da produtividade em progresso técnico, economias de escala e utilização da capacidade.

A produtividade total dos fatores na agricultura brasileira, no período 1955-1994, cresce à taxa anual de $0,8 \%$. Este desempenho é fortemente influenciado pelo comportamento da mudança técnica no período 1955-1975. Apesar do esforço realizado para implementação de mecanismos de transformação do sistema produtivo, não se pode verificar o efeito deslocamento da função custo. O deslocamento desta função, que estaria captando o efeito do progresso técnico e da melhoria das práticas gerenciais aparece com o sinal negativo nos vinte anos iniciais do período analisado. Entretanto, a constatação de expressivos retornos à escala, neste período, pode estar refletindo também algum efeito da incorporação de novas técnicas. 
Somente em períodos mais recentes, 1975-1994 e 1980-1994, a agricultura vem experimentando mudança técnica de forma significativa para explicar os ganhos de produtividade total. No período 1975-1994, por exemplo, a PTF cresce à taxa anual de aproximadamente 2,0\%. Este fato coincide com a consolidação e fortalecimento dos elos de ligação entre o setor agrícola e o setor industrial.

Deve-se destacar ainda o efeito dos retornos à escala sobre a produtividade total da agricultura. Este componente mantém-se estável ao longo dos quatro períodos sob analise e contribui de modo substantivo para reduzir o impacto negativo da mudança técnica no período 1955-1975. A utilização da capacidade é também relevante para a determinação da produtividade total, porém, vem perdendo importância ao longo dos anos.

Não menos relevante é a conclusão sobre contribuição que os ganhos de produtividade acarretam sobre a produção. No período 1955-1994, verifica-se um crescimento de $2,6 \%$ a.a. da produção agropecuária. Para esse desempenho, o fator trabalho contribuiu com 40,3\%, a terra com 28,4\% e a PTF com 31,2\%. Entretanto, no período 1980-1994, a PTF passa a ser o principal determinante do crescimento do produto social da agricultura e chega a se responsabilizar por $90 \%$ de seu crescimento.

A agricultura brasileira, a partir de meados da década de 70, apresenta bons resultados decorrentes da mudança técnica. A incorporação de novos processos e técnicas de produção passa a ser, então, observada. 
Quer isto dizer que a modernização agrícola não é apenas um plano, função de uma política, ou de um mandato governamental. É um processo dinâmico que não representa rotina, e, muito menos, é resultante de uma administração agrícola rotineira. A modernização não tem por característica o equilíbrio estacionário de uma agricultura tradicional. Trata-se, na verdade, de um processo de longo prazo, assim como o de desenvolvimento econômico.

Neste sentido, as contribuições da pesquisa agrícola, para reduzir os entraves físicos, biológicos e mecânicos, tornam possíveis novas oportunidades para aumentar a produção. No Brasil, recuperar e aumentar continuamente os investimentos em pesquisa são questões essenciais para a manutenção de altos índices de produtividade na agricultura.

Novas pesquisas devem ser realizadas para investigar o comportamento das taxas de crescimento da produtividade em culturas e criações, bem como sua influência sobre a determinação do produto. O entendimento do comportamento da PTF nas principais regiões do país também merece atenção dos pesquisadores, a fim de que se possam reduzir possíveis entraves à mudança técnica, aos retornos à escala e à utilização da capacidade. Para o desenvolvimento dessas pesquisas, as estatísticas censitárias de 1996 serão essenciais.

Concluindo, é importante enfatizar que as bases teóricas do modelo de modernização implicaram, no passado, forte interferência do Estado, sob a forma de 
crédito subsidiado, políticas de preços e facilidades para a produção doméstica de fertilizantes químicos e máquinas agrícolas. Hoje, a modificação na condução dos instrumentos de politica econômica não significa, necessariamente, que a estagnação do processo de modernização está por acontecer. Os resultados desta pesquisa indicam justamente o contrário. O que se observa é um ajuste do setor a um novo cenário, com escassez de recursos financeiros, abertura comercial e mudanças nas relações de produção e comercialização. Nesta fase de difícil ajuste, é ainda imprescindível a presença do Estado, face às vantagens comparativas do setor na economia brasileira e à importância social das funções da agricultura no crescimento econômico. 


\section{REFERÊNCIA BIBLIOGRAFICA}

AGUIRRE, B.M.B.; BACHA, C.J.C. A especialização da mão-deobra rural no Brasil. In: CONGRESSO BRASILEIRO DE ECONOMIA E SOCIOLOGIA RURAL, 27., Piracicaba, 1983. Anais. Brasilia: SOBER, 1989. p.572-584.

ALBUqueRque, M.C.C. Uma análise translog sobre mudança tecnológica e efeitos de escala: um estudo de modernização ineficiente. Pesquisa e planejamento Econômico, V.17, n.1, p.191-220, abr.1987.

ALMEIDA, A. Mercados informais como fonte alternativa de Iiquidez para os agricultores. Piracicaba, 1994. 204p. Dissertação (M.S.) - Escola Superior de Agricultura "Luiz de Queiroz", Universidade de São Paulo.

ALVES, E.; CONTINI, E. A modernização da agricultura brasileira. In.: BRANDÃO, A.S. Os principais problemas da agricultura brasileira: análise e sugestões. 2.ed. Rio de Janeiro: PNPE/IPEA, 1992. p.49-88.

ALVES, E.R. A produtividade da agricultura brasileira. Brasilia: EMBRAPA, 1979. $34 \mathrm{p}$.

ALVES, E.R.; PASTORE, J. Uma nova abordagem para a pesquisa agrícola no Brasil. Revista de Economia rural. V.15, n.1, p.235-256, 1977 .

ARAúJo, P.F.C.; BARROS,A.L.M.; AlmEIDA, A. sobre o

financiamento da agricultura brasileira. São Paulo: MBA, 
140 p. (Relatório Projeto BM\&F Agrícola) ARAÚJO, P.F.C.; MEYER, R.L. Política de crédito agrícola no Brasil: objetivos e resultados. In: VEIGA, A.

Ensaios sobre politica agricola brasileira. São Paulo: Secretaria de Agricultura, 1979. p.137-162.

ARNADE, C.A. Productivity and technical change in Brazilian Agriculture. United States Department of Agriculture. Economic Research Service. Washington, DC Bulletin Number 1811, Nov.1992.

Associação Nacional dos Fabricantes de Veículos Automotores. Anuário Estatistico da Indústria Automobilistica Brasileira. São Paulo: ANFAVEA, 1996.

ÁVILA, A.F.D.; EVENSON, R.E. Total factor productivity growth in the Brazilian Agriculture and the role of Agricultural Research. In: CONGRESSO BRASILEIRO DE ECONOMIA E SOCIOLOGIA RURAL,33., Curitiba, 1995. Anais. Brasilia: SOBER, 1995. p.631-657.

BACHA. C.J.C.; ROCHA, M. T. O comportamento da agropecuária brasileira no período de 1987 a 1996. Revista Brasileira de Economia e Sociologia Rural, V.36, n.1, p.35-59, jan./mar. 1998.

BARROS, J.R.M. Política e desenvolvimento agrícola no Brasil. In: VEIGA, A. Ensaios sobre politica agricola brasileira. São Paulo: Secretaria de Agricultura, 1979. p. $9-35$.

BARROS, J.R.M. Transição e descontinuidade no crescimento agrícola. In: DIAS, G.L.S.; BARROS, J.R.M. Fundamentos de uma nova politica agricola. Brasilia: CFP, 1983. 39p. (Coleção Análise e Pesquisa, 26) BARROS, J.R.M.; GRAHAM, D.H. A agricultura brasileira e o 
problema da produção de alimentos. In: SEMINÁRIO SOBRE ECONOMIA DA TECNOLOGIA, 1., São Paulo, 1978. São Paulo. $35 \mathrm{p}$.

BARROS, J.R.M.; MANOEL, A. Insumos agrícolas: evolução recente e perspectivas. In: BRANDÃO, A.S. Os principais problemas da agricultura brasileira: análise e sugestões. Rio de Janeiro: PNPE/IPEA, 1992. p.295-332.

BEATTIE, B.R.; TAYLOR, C.R. The economics of production. New York: John Wiley \& Sons, 1985. 258p.

BEHRENS, R.; HAEN, H. Aggregate factor input and productivity in agriculture: a comparison for the ECmember countries - 1963-76. European Review of Agricultural Economics, V.7, n.2, p.109-146, 1980.

BINSWANGER, H.P. The measurement of technical change biases with many factors of production. The American Economic Review, v.64, n.6, p.964-976, Dec.1974.

BINSWANGER, H.P. A cost function approach to the measurement of elasticities of substitution. American Journal of Agricultural Economics, v.56, n.2, p.377-86, May 1974.

BRAGA, H.C.; ROSSI; J.W. Produtividade total dos fatores de produção na indústria brasileira: mensuração e decomposição de sua taxa de crescimento. Brasília: IPEA, 1998. (Texto para discussão interna, 157).

BRANDÃO, A.S.P.; ALVES, E. Elementos de uma estratégia para o desenvolvimento da agricultura brasileira. Ensaios Econômicos. EPGE, n.209, 1993. $370 p$.

CAMPos, A.C. Caracterização do crescimento na agricultura. In: CONGRESSO BRASILEIRO DE ECONOMIA E SOCIOLOGIA RURAL, 20., Curitiba, 1982. Anais. Brasília: SOBER, 1982. 
p. $383-393$

CAVALLO, D.; MUNDLAK, Y. Agriculture and economic growth in economy: the case of Argentine. IFPRI Research Report, n.36, Dec.1982.

CHRISTENSEN, L.R. Concepts and measurement of Agricultural productivity. American Journal of Agricultural Economics, V.57, n.5, p.910-915, Dec. 1975.

DE JANVRY, A. Social structure and biased technical change in Argentine Agriculture. In: BINSWANGER, H. P.; RUTTAN, V.W. Induced inovation: technology, institutions and development. Baltimore: Johns Hopkins University Press, 1978. p. 297-323.

DENINSON, E.F. The sources of economics growth in the United states. Supp.pap. 13. Committee for Economic Development. Washington, 1962.

DENNY, M.; FUSS, M.; WAVERMAN, L. The measurentand interpretation of total factor productivity in regulated industries with an application to Canadian telecommunications. In: COWING, T.; STEVENSON, R. (Eds.). Productivity measurement in regulated industries. New York: Academic Press, 1981. 471p.

DIAS, G.L.S. Avanços e perspectivas do Agrobusiness brasileiro. In: CONGRESSO BRASILEIRO DE ECONOMIA E SOCIOLOGIA RURAL, 31. Ilhéus, 1993. Anais. Brasília: SOBER, 1993. p.887-895.

DIAS, G.L.S.; BARROS,A.L.M. Situação da agricultura no Brasil e no mundo. São Paulo: MBA, 1998. 140 p. (Relatório Projeto BM\&F Agrícola)

DIAS, R.S. Elasticidades de substituição e de demanda por fatores na agricultura brasileira. Viçosa, 1982. 55p. 
Dissertação (M.S.) - Departamento de Economia Rural, Universidade Federal de Viçosa.

EVENSON, R. Notes on the measurement of the economic consequences of agricultural research investments. In: LEE, D.R.; KEARL S.; UPHOFF, N. Assessig the impact of international agricultural research for sustainable development. New York: CIIFAD, 1992.

FUNDAÇÃO INSTITUTO BRASILEIRO DE ESTAÍSTICA E GEOGRAFIA. Estatisticas históricas do Brasil: séries econômicas, demográficas e sociais de 1950 a 1985. Rio de Janeiro: IBGE, 1986. (Séries Estatisticas Retrospectivas, n.3).

FUNDAÇÃO INSTITUTO BRASILEIRO DE ESTATÍSTICA E GEOGRAFIA. Anuário Estatístico do Brasil. Rio de Janeiro: IBGE, $1960-1994$.

FUNDAÇÃO INSTITUTO BRASILEIRO DE ESTATÍSTICA E GEOGRAFIA. Pesquisa Nacional por Amostra de Domicílios. Rio de Janeiro: IBGE, 1975-1994.

FUNDAÇÃO INSTITUTO BRASILEIRO DE GEOGRAFIA E ESTATÍSTICA. Pesquisa Agrícola Municipal. Rio de Janeiro: IBGE, 1975-1994.

FUNDAÇÃO INSTITUTO. BRASILEIRO DE GEOGRAFIA E ESTATÍSTICA. Pesquisa Pecuária Municipal. Rio de Janeiro: IBGE, $1975-1994$.

FUSS, M.; WAVERMAN, L. The extent and sources of cost and efficiency differences between United states and Japanese Automobile Producers. N.B.E.R. Working Paper 1849, mar. 1986.

GASQUES, J.G.; CONCEIÇÃO, J.C.P.R. Crescimento e produtividade da agricultura brasileira. Brasilia: IPEA/CGPOP. Brasília, 1997. (Texto para Discussão n.502) 
GREENE, W.H. Econometric analysis. 3ed. Prentice hall: Upper Saddle River, 1997. 1075p.

HAYAMI, Y.; RUTTAN, V. Preços dos fatores e mudança técnica no desenvolvimento da agricultura: Estados Unidos e Japão, 1880-1960. In: ARAÚJO, P.F.C.; SCHUH, G.E. Desenvolvimento da Agricultura: educação pesquisa e assistência técnica. São Paulo: Pioneira,1975. p.53-76.

HAYAMI, Y.; RUTTAN, V. Agricultural development: an international perspective. Baltimore: Johns Hopkins Press, 1985. $361 \mathrm{p}$.

HAYAMI, Y.; YAMADA, S. Progresso tecnológico na agricultura. In: ARAÚJO, P.F.C.; SCHUH, G.E. Desenvolvimento da agricultura: estudos de casos. São Paulo: Pioneira, 1983. p.31-56.

HOFFMANN, R. ; JAMAS, A.L. A produtividade da terra e do trabalho na agricultura de 332 microrregiões do Brasil. In: CONGRESSO BRASILEIRO DE ECONOMIA E SOCIOLOGIA RURAL, 28. Florianópolis, 1990. Anais. Brasília: SOBER, 1990. p. 21-40.

HOFFMANN, R. et al. Inovações tecnológicas transformações. recentes na agricultura brasileira. Piracicaba, 1985. 4v. (Relatório de Pesquisa, FINEP / FEALQ/ESALQ) .

HOMEM DE MELO, F.B. Agricultura brasileira: incerteza e disponibilidade de tecnologia. São Paulo, 142p. Tese (Livre-Docência) - Faculdade de Economia, Administração e Contabilidade, Universidade de São Paulo.

HOMEM DE MELO, F.B. Disponibilidade de tecnologia produtos da agricultura brasileira. Revista de Economia Rural, v.18, n.2, p.221-50, abr/jun 1980 . 
HOMEM DE MELO, F.B. O crescimento agrícola brasileiro dos anos 80 e as perspectivas para os anos 90. Revista de Economia Política, V.10, n.3, p.22-39, set. 1990.

JOHNSON, R.A.; WICHERN, D.W. Applied multivariate statistical analysis. Englewood Cliffs, N.J.: Prentice Hall, 1982. 594p.

KAGEYAMA, A. Problemas metodológicos na mensuração do emprego agrícola. Campinas: Instituto de Economia; UNICAMP, 1986. (mimeo).

KAGEYAMA, A.A.; SILVA, J.G. Produtividade e emprego na agricultura brasileira. In:

Desenvolvimento

capitalista no Brasil $\mathrm{n}$ ㅇ 2 : ensaios sobre a crise. São Paulo: Ed. Brasiliense, 1983. p.192-222.

KENDRICK, J.W. Productivity trends in the United states. Princeton N.J.: Princenton University Press, 1961. $630 \mathrm{p}$.

KMENTA, J.; GILBERT, R.F. Small sample properties of alternative estimators of seemingly unrelated regressions. Journal of the American Statistical Association, V.60, Dez.1968.

KUZNETS, S. Economic growth and the contribution of agriculture: notes on measurements. In: EICHER, C.K.; WITT, L.W. (eds.). Agriculture in economic development. New York: McGraw-Hill, 1964. cap. 5 .

KUZNETS, S. Modern economic growth, rate, structure and spread. New Haven; Yale University Press, 1974. 529p. KUZNETS, S. Crescimento econômico moderno: descobertas e reflexões. Conferência Nobel. Revista Brasileira de Economia, v.39, n.2, p.225-39, abr./jun.1985. KWON, J.K. Capital, utilization, economies of scale and 
technical change in the growth of total factor productivity: an explanation of south Korean manufacturing growth. Journal of Development Economics, V.24, n.1, p.75-89, 1986.

LEONE, E.T. Modernização e distribuição de renda na agricultura no Estado da Bahia em 1980. Piracicaba, 1988. 152p. Dissertação (Mestrado) - Escola Superior de Agricultura "Luiz de Queiroz", Universidade de São Paulo. LOPES, M.R. Alguns efeitos das políticas agrícolas sobre o processo técnico na agricultura. Carta mensal da supec, v.2, n.8, 1987 .

MARTINE, G. Fases e faces da modernização agrícola brasileira. Planejamento e Politicas Públicas. n.3, jun.1990.

MONTEIRO, J.A. A geração de tecnologia agrícola e a ação dos grupos de interesses. São Paulo,1984. 186p. Tese (Doutorado) - Faculdade de Economia Administracão e Contabilidade, Universidade de são Paulo.

MORRISON, C.J. Productivity measurement with non static expectations and varying capacity utilization: an integrated approach. Journal of Econometrics, V.33, n.1, p. 51-74, Oct/Nov. 1986.

NADIRI, M.I. Some approaches to the theory and measurement of total factor productivity: a survey.

Economic Literature, V.8, n.4, Dec. 1970.

OHTA, M. A note on the duality between production and cost function: rates of returns to scale and rate of technical progress. Economic studies Quarterly, V.25, n.1, p.63-65, 1975 .

ROSEGRANT, M.W.; EVENSON, R.E. Agricutural productivity and 
sources of growth in South Asia. American Journal of Agricultural Economics, v.74, n.3, Aug. 1992.

SANTOS, R.F. Presença de viéses de mudança técnica na agricultura brasileira. São Paulo, 1986. 223p. Tese (Doutorado) - Faculdade de Economia, Administração e Contabilidade, Universidade de são Paulo.

SCHUH, G, E.; ALVES, E.R. O desenvolvimento da agricultura no Brasil. Rio de Janeiro: APEC, 1971. 369p.

SCHULTZ, T.W. A transformação da agricultura tradicional. Rio de Janeiro: Zahar, 1965. 207p.

SILVA, G.L.S.P. Contribuição da pesquisa e extensão rural para a produtividade agrícola: O caso de São Paulo. Estudos Econômicos, v.14,n.2, p.315-53, maio/ago. 1984. SILVA, G.L.S.P.; CARMO, H.C.E. Como medir a produtividade agrícola: conceitos, métodos e aplicação no caso de são Paulo. Agricultura em são Paulo, v.33,n.1/2, p. 139-170, 1986.

SILVA, G.L.S.P. Evolução dos determinantes da produtividade agrícola: o caso da pesquisa e da extensão rural em São Paulo. São Paulo, 1982. 230p. Tese (Doutorado) - Faculdade de Economia, Administração e Contabilidade, Universidade de são Paulo.

SILVA, G.L.S.P.; FONSECA, M.A.S.; MARTIN, N.B. Investimento na geração e difusão de tecnologia agrícola no Brasil. Revista de Economia Rural, v.18, n.2, p.327338. abr./jul. 1980.

SILVA, J.G. Por um novo paradigma agrário. In: CONGRESSO BRASILEIRO DE ECONOMIA E SOCIOLOGIA RURAL, 31., Ilhéus, 1993. Anais. Brasilia: SOBER, 1993. p.956-972. SOLOW, R.M. Technical change and the aggregate production 
function. Review of Economics and statistics, v.39, n.3, p. 312-20, Aug. 1957.

VARIAN, H.R. Intermediate microeconomics: a modern approach. New York: W.W. Norton \& Company, 1987. 587p. VARIAN, H.R. Microeconomics analysis. New York. W.W. Norton \& Company, 1984. 348p .

VERA FILHO, F.; TOLLINI, H. Progresso tecnológico e desenvolvimento Agrícola. In: VEIGA, A., (Coord.). Ensaios sobre Politica Agrícola brasileira. São Paulo: Secretaria da Agricultura, 1979. p.87-136.

ZELLNER, A. An efficient method of estimating seemingly unrelated equations and tests for aggregation bias. Journal of the Americam Statistical Association, V.57, n.2, p. 348-68, 1962 . 
Apêndice 1

ÍNDICE DE Torńquist 


\section{Indice de Tornqvist}

O cálculo do índice de quantidade do produto e o índice agregado de insumos, foi obtido a partir da definição do indice de Tornquistutilizado para a obtenção da produtividade total dos fatores, definido como:

$$
P T F_{t} / P T F_{t-1}=\frac{\pi_{i=1}^{n}\left(\frac{Y_{i t}}{Y_{i t-1}}\right)^{\frac{s_{i t}+S_{i t-1}}{2}}}{\pi_{j=1}^{m}\left(\frac{X_{i t}}{X_{i t-1}}\right)^{\frac{C_{t h}+C_{i t-1}}{2}}}
$$

Nesta expressão, os termos $Y i$ e Xj são, respectivamente, as quantidades dos produtos e dos insumos; $S_{i} e$ $c_{j}$ são, respectivamente, as participações do produto i no valor agregado dos produtos e do insumo j no custo total dos insumos.

Aplicando-se logaritmos à expressão acima, chega-se a formulação g̣eral de Divisia que é a seguinte:

$$
\begin{aligned}
& \text { In } \quad\left(P_{t} / P T F_{t-1}\right)=\frac{1}{2} \sum_{i=1}^{n}\left(S_{i t}+S_{i t-1}\right) \text { In }\left(\frac{Y_{i t}}{Y_{i t-1}}\right) \\
& -\frac{1}{2} \sum_{j=1}^{m}\left(C_{j t}+C_{j t-1}\right) \text { In }\left(\frac{X_{j t}}{X_{j t-1}}\right) \\
& \text { O primeiro termo refere-se ao indice agregado de }
\end{aligned}
$$
produto, utilizado para o cálculo de $\left(I_{Q}\right)$, e o segundo, ao índice agregado de insumos, utilizado no cálculo de F. 
Apêndice 2

DADOS BÁSICOS DA PESQUISA 
Tabela 5. Dađos básicos para estimação da função custo para a agricultura brasileira. Período 1955-1994.

\begin{tabular}{|c|c|c|c|c|c|c|}
\hline \multirow{3}{*}{ Ano } & \multirow[b]{2}{*}{ Custo (a) } & \multicolumn{3}{|c|}{ Preços $^{(\mathbf{a})}$} & \multirow{2}{*}{$\begin{array}{l}\text { Índice de } \\
\text { Quantidade }\end{array}$} & \multirow{2}{*}{$\begin{array}{l}\text { Utilização da } \\
\text { Capacidade }\end{array}$} \\
\hline & & Máquina & Terra & Trabalho & & \\
\hline & $(\mathrm{C})$ & $\left(\mathrm{P}_{\mathrm{M}}\right)$ & $\left(\mathrm{P}_{1}\right)$ & $\left(\mathrm{P}_{\mathrm{L}}\right)$ & $\left(\mathrm{I}_{Q}\right)$ & $\left(I_{C^{\circ}}\right)$ \\
\hline 1955 & 8345501228,36 & 692,82 & 324,18 & 511,53 & 42,56995 & 42,21155 \\
\hline 1956 & 8493407531,09 & 643,50 & 332,63 & 426,58 & 42,52206 & 43,10302 \\
\hline 1957 & 8049294497,93 & 616,40 & 289,68 & 498,07 & 45,40321 & 45,23135 \\
\hline 1958 & 8586289908,20 & 555,49 & 313,69 & 440,71 & 46,50082 & 45,74269 \\
\hline 1959 & 8240512184,00 & 927,04 & 286,49 & 399,65 & 50,40226 & 47,80348 \\
\hline 1960 & 7361560616,74 & 748,61 & 235,24 & 340,30 & 51,48836 & 50,93519 \\
\hline 1961 & 10656899434,86 & 633,76 & 342,56 & 383,69 & 52,85191 & 52,73357 \\
\hline 1962 & 12565217133,68 & 862,76 & 395,62 & 372,05 & 54,24288 & 55,00275 \\
\hline 1963 & 1336() $239958,99$ & 1008,46 & 402,87 & 360,92 & 54,57323 & 57,86240 \\
\hline 1964 & 13644473563,89 & 1110,14 & 394,74 & 440,38 & 55,77838 & $59,(04909$ \\
\hline 196.5 & $1746(0986145,81$ & 965,69 & 496,47 & 339,97 & 59,75604 & $63,0742()$ \\
\hline 1966 & 13821913750,32 & 803,14 & 392,29 & 351,44 & 58,36103 & 61,79296 \\
\hline 1967 & 11845457549,71 & 849,83 & 322,10 & 356,59 & 59,47418 & 63,21120 \\
\hline 1968 & 10697544219,61 & 812,98 & 280,44 & 349,61 & 60,15072 & 64,76258 \\
\hline 1969 & 10995497665,10 & 823,05 & 278,87 & 358,42 & 61,51273 & 66,72883 \\
\hline 1970 & 10787586841,80 & 664,24 & 257,82 & 381,03 & 62,12821 & 69,25465 \\
\hline 1971 & 10673306043,17 & 626,09 & 242,16 & 368,56 & $65,4(1291$ & 72,87455 \\
\hline 1972 & $126260) 8218,65$ & 620,28 & 275.18 & 485,10 & 66,76043 & 74,53013 \\
\hline 1973 & 14019711514,50 & 562,09 & 299,05 & 609,45 & 64,17687 & 74,31595 \\
\hline 1974 & 24990637283,51 & 488,11 & 539,32 & 645.03 & 66,21619 & 79.786 .31 \\
\hline 1975 & $28(0052516699,79$ & 493.24 & 348.24 & $6.32,66$ & $7(0,2948.3$ & 83.68758 \\
\hline 1976 & $249572(04689,83$ & 393,31 & 313,03 & 765,65 & 69,95572 & 86,06405 \\
\hline 1977 & 24869518372,59 & 418,67 & 330,55 & 612,76 & 79,33021 & 91,03169 \\
\hline 1978 & 23370919218,02 & 332,00 & 312,28 & 603,71 & 77,35455 & 90,40389 \\
\hline 1979 & 24310662517,69 & 340,76 & 319,20 & 622,72 & 80,62802 & 92,79583 \\
\hline 1980 & 23857950543,92 & 347,84 & 335,64 & 570,29 & 85,10457 & 95,54788 \\
\hline 1981 & 26589615213,03 & 486,20 & 383,26 & 593,04 & 89,53406 & 94,09033 \\
\hline 1982 & 26610497014,94 & 523,11 & 376,90 & 516,33 & 88,87905 & 98,79265 \\
\hline 1983 & 23159913117,21 & 618,40 & 355,62 & 535,81 & 88,62275 & 87,46088 \\
\hline 1984 & 25996170714,06 & 468,78 & 376,62 & 481,36 & 91,94287 & 96,15845 \\
\hline 1985 & 28442467144,45 & 577,43 & 403,39 & 494,62 & 100,00000 & 100,00000 \\
\hline 1986 & 30669045876,72 & 432,40 & 418,19 & 573,35 & 92,72549 & 103,50920 \\
\hline 1987 & 25395564464,36 & 589,43 & 363,54 & 417,24 & 100,23602 & 103,41039 \\
\hline 1988 & 32910913565,24 & 620,84 & 495,39 & 380,54 & 102,77269 & 107,02173 \\
\hline 1989 & 33182100311,19 & 554,45 & 484,39 & 456,21 & 105,74000 & 106,61817 \\
\hline 1990 & 24738439619,15 & 338,69 & 395,91 & 333,68 & 102,41844 & 97,47228 \\
\hline 1991 & $243419912(04,38$ & 547,28 & 425,89 & $22(0,30$ & 104,23156 & 97,72154 \\
\hline 1992 & 24107108398,99 & $708,(09$ & 386,76 & 299,95 & 108.23968 & 97,85813 \\
\hline 1993 & 29649587933,50 & 663,00 & 519,62 & 368,57 & 107,00014 & 89,97509 \\
\hline 1994 & 21524752875,94 & 262,20 & 351,50 & 244,88 & 112,37418 & 99,09185 \\
\hline
\end{tabular}


Tabela 6. Participações observadas dos fatores no custo. Período 1955-1994.

\begin{tabular}{|c|c|c|c|}
\hline \multirow[t]{2}{*}{ Ano } & \multicolumn{3}{|c|}{ Participações } \\
\hline & $\begin{array}{l}\text { Máquinas } \\
\left(S_{M}\right)\end{array}$ & $\begin{array}{l}\text { Terra } \\
\left(\mathrm{S}_{\mathrm{r}}\right) \\
\end{array}$ & $\begin{array}{c}\text { Trabalho } \\
\left(\mathrm{S}_{\mathrm{L}}\right) \\
\end{array}$ \\
\hline 1955 & 0,000040 & 0,102959 & 0,897092 \\
\hline 1956 & 0,000040 & 0,143400 & 0,856662 \\
\hline 1957 & 0,000043 & 0,159175 & 0,841003 \\
\hline 1958 & 0,000043 & 0,213169 & 0,787126 \\
\hline 1959 & 0,000077 & 0,234951 & 0,765314 \\
\hline 1960 & 0,000073 & 0,266433 & 0,734083 \\
\hline 1961 & 0,000067 & 0,259068 & 0,741212 \\
\hline 1962 & 0,000100 & 0,264597 & 0,735577 \\
\hline 1963 & 0,000130 & 0,243807 & 0,756331 \\
\hline 1964 & 0,000159 & 0,170060 & 0,829977 \\
\hline 1965 & 0,000148 & 0,140286 & 0,859590 \\
\hline 1966 & 0,000132 & 0,278052 & 0,722084 \\
\hline 1967 & 0,000145 & 0,286361 & 0,714011 \\
\hline 1968 & 0,000148 & 0,299943 & 0,700702 \\
\hline 1969 & 0,000159 & 0,302909 & 0,697780 \\
\hline 1970 & 0,000139 & 0,288275 & 0,713005 \\
\hline 1971 & 0,000147 & 0,342161 & 0,659739 \\
\hline 1972 & 0,000166 & 0,320664 & 0,682220 \\
\hline 1973 & 0,000174 & 0,325230 & 0,678083 \\
\hline 1974 & 0,000175 & 0,359274 & 0,642939 \\
\hline 1975 & 0,001006 & 0,539304 & 0,459690 \\
\hline 1976 & 0,000988 & 0,559441 & 0,439571 \\
\hline 1977 & 0,000805 & 0,627043 & 0,372152 \\
\hline 1978 & 0,000583 & 0,626028 & 0,373389 \\
\hline 1979 & 0,000686 & 0,631441 & 0,367873 \\
\hline 1980 & 0,000732 & 0,696624 & 0,302644 \\
\hline 1981 & 0,000511 & 0,702855 & 0,296634 \\
\hline 1982 & 0,000484 & 0,725165 & 0,274351 \\
\hline 1983 & 0,000602 & 0,695976 & 0,303422 \\
\hline 1984 & 0,000751 & 0,721975 & 0,277274 \\
\hline 1985 & 0,000827 & 0,735007 & 0,264166 \\
\hline 1986 & 0,000639 & 0,731455 & 0,267906 \\
\hline 1987 & 0,000901 & 0,767173 & 0,231926 \\
\hline 1988 & 0,000564 & 0,834861 & 0,164575 \\
\hline 1989 & 0,000440 & 0,806599 & 0,192961 \\
\hline 1990 & 0,000291 & 0,808438 & 0,191271 \\
\hline 1991 & 0,000303 & 0,886065 & 0,113631 \\
\hline 1992 & 0,000344 & 0,813630 & 0,186026 \\
\hline 1993 & 0,000478 & 0,817202 & 0,182320 \\
\hline 1994 & 0,000469 & 0,838617 & 0,160914 \\
\hline
\end{tabular}

Fonte: Dados da pesquisa 
Apêndice 3

ESTIMATIVAS DOS PARÂMETROS DA FUNÇÃO CUSTO TRANSLOG 
Tabela 7. Estimativa dos parâmetros da função custo translog, restrita, para a agricultura brasileira. Modelo com a constante e variável "dummy". Período 1955-1994.

\begin{tabular}{|c|c|c|c|}
\hline Parâmetro ${ }^{(a)}$ & Estimativa & Erro-Padrão & \\
\hline$\alpha_{0}$ & -122.7451 & 78.3693 & $* * * *$ \\
\hline Dummy 1 & 0.0017 & 0.1524 & \\
\hline$\alpha_{\mathrm{T}}$ & -4.2070 & 0.7618 & $*$ \\
\hline$\alpha_{1}$ & 5.2686 & 0.3847 & $*$ \\
\hline$\alpha_{N I}$ & -0.0616 & 0.1201 & \\
\hline$\gamma_{\mathrm{Tr}}$ & -0.0203 & 0.0259 & \\
\hline$\gamma_{11}$ & 0.0202 & 0.0151 & \\
\hline$\gamma_{\mathrm{mM}}$ & 0.0001 & 0.0010 & \\
\hline$\gamma_{\text {NMI }}$ & 0.0024 & 0.0153 & \\
\hline$\gamma_{\mathrm{NI}}$ & -0.0025 & 0.0008 & $*$ \\
\hline$\gamma_{1,1}$ & $-(0.0177$ & 0.1651 & \\
\hline$a_{Q}$ & 109.5978 & 27.1542 & $*$ \\
\hline$a_{Q Q}$ & -9.9538 & 6.2351 & \\
\hline$\sigma_{\mathrm{QL}}$ & -1.1076 & 0.0521 & $*$ \\
\hline$\sigma_{\mathrm{QT}}$ & 1.1030 & 0.2204 & $*$ \\
\hline$\sigma_{\mathrm{QN}}$ & 0.0046 & 0.0088 & \\
\hline$\theta_{r}$ & -0.2977 & 0.1093 & $*$ \\
\hline$\theta_{M}$ & -0.0095 & 0.0043 & $* *$ \\
\hline$\theta_{1}$ & 0.3072 & 0.0127 & $*$ \\
\hline$\delta_{\mathrm{T}}$ & 0.2873 & 0.1650 & $* * *$ \\
\hline$\delta_{M}$ & 0.0172 & 0.0068 & $*$ \\
\hline$\delta_{1}$ & -0.3045 & 0.0291 & $*$ \\
\hline$\beta_{\mathrm{t}}$ & -52.3455 & 27.2820 & $* *$ \\
\hline$\beta_{\mathrm{tt}}$ & -4.5202 & 2.3746 & $* * *$ \\
\hline$\theta_{\mathrm{Q}}$ & 16.7115 & 5.4088 & $*$ \\
\hline$\delta_{\mathrm{Q}}$ & -18.0060 & 8.7124 & $* *$ \\
\hline$\delta_{\mathrm{t}}$ & 2.1785 & 7.3785 & \\
\hline$\rho_{\lambda}$ & -6.7144 & 42.5075 & \\
\hline$\rho_{\lambda \lambda}$ & 9.1609 & 6.8864 & \\
\hline
\end{tabular}

Fonte: Dados da pesquisa

Nota: $R^{2}=0,9474$

(a) Definidos conforme equação (8)

* significativo ao nível de 1 .

* * significativo ao nível de $5 \%$

** significativo ao nivel de 10 . 
Tabela 8. Estimativa dos parâmetros das funções de parcela, terra e mão-deobra, da agricultura brasileira. Modelo com a constante e variável "dummy". Período 1955-1994.

\begin{tabular}{|c|c|c|c|}
\hline Parâmetro ${ }^{(\mathrm{a})}$ & Estimativa & Erro-Padrão & \\
\hline Parcela Terra & & $\mathrm{R}^{2}=0$, & 9520 \\
\hline$\alpha_{1}$ & 4.5451 & 0.7332 & $*$ \\
\hline Dummy 2 & 0.0193 & 0.0488 & \\
\hline$\gamma_{\mathrm{TT}}$ & -0.0203 & 0.0259 & \\
\hline$\gamma_{\mathrm{TM}}$ & 0.0001 & 0.0010 & \\
\hline$\gamma_{\mathrm{Tl}}$ & 0.0202 & 0.0151 & \\
\hline$\sigma_{\mathrm{QT}}$ & 1.1030 & 0.2204 & $*$ \\
\hline$\theta_{\mathrm{T}}$ & -0.2977 & 0.1093 & $*$ \\
\hline$\delta_{\mathrm{r}}$ & 0.2873 & 0.1650 & $* * *$ \\
\hline Parcela Mão-de-obra & & $\mathrm{R}^{2}=0$, & 9488 \\
\hline$\alpha_{2}$ & 5.6096 & 0.7588 & $*$ \\
\hline Dummy 3 & -0.0189 & 0.0504 & \\
\hline$\gamma_{1, L}$ & -0.0177 & 0.1651 & \\
\hline$\gamma_{\mathrm{MII}}$ & -0.0025 & 0.0008 & $*$ \\
\hline$\gamma_{\mathrm{Tl}}$ & 0.0202 & 0.0151 & \\
\hline$\sigma_{\mathrm{QL}}$ & -1.1076 & 0.0521 & $*$ \\
\hline$\theta_{\mathrm{L}}$ & 0.3072 & 0.0127 & $*$ \\
\hline$\delta_{\mathrm{L}}$ & -0.3045 & 0.0291 & $*$ \\
\hline
\end{tabular}

Fonte: Dados da pesquisa

Nota: (a) Definidos conforme equação (9)

* significativo ao nível de 18

** significativo ao nível de 5 .

** significativo ao nível de $10 \%$ 
Tabela 9. Estimativa dos parâmetros da função custo translog, restrita, para a agricultura brasileira. Modelo com a constante. Período 1955-1994.

\begin{tabular}{|c|c|c|c|}
\hline Parâmetro ${ }^{(\mathrm{a})}$ & Estimativa & Erro-Padrão & \\
\hline$\alpha_{1}$ & -121.288364 & 77.65296 & \\
\hline$\alpha_{i}$ & -4.436052 & 0.51355 & $*$ \\
\hline$\alpha_{1}$ & 5.493118 & 0.72890 & $*$ \\
\hline$\alpha_{M}$ & -0.057066 & 0.11647 & \\
\hline$\gamma_{\mathrm{TT}}$ & -0.017568 & 0.00170 & $*$ \\
\hline$\gamma_{\mathrm{rl}}$ & 0.017260 & 0.01415 & \\
\hline$\gamma_{m}$ & 0.000308 & 0.00096 & \\
\hline$\gamma_{M M}$ & 0.002266 & 0.01120 & \\
\hline$\gamma_{N 11}$ & -0.002575 & 0.00079 & $*$ \\
\hline$\gamma_{1,1}$ & -0.014685 & 0.14170 & \\
\hline$a_{Q}$ & 113.130501 & 26.60198 & $*$ \\
\hline$a_{Q Q}$ & -11.777058 & 5.58716 & $* *$ \\
\hline$\sigma_{\mathrm{QL}}$ & $-1.170(021$ & 0.01690 & $*$ \\
\hline$\sigma_{Q T}$ & 1.167453 & 0.12575 & $*$ \\
\hline$\sigma_{\mathrm{QM}}$ & 0.002 .568 & 0.00501 & \\
\hline$\theta_{\mathrm{T}}$ & -0.321549 & 0.09322 & $*$ \\
\hline$\theta_{\mathrm{N}}$ & -0.008892 & 0.00362 & $*$ \\
\hline$\theta_{\mathrm{l}}$ & 0.330441 & 0.00930 & $*$ \\
\hline$\delta_{\mathrm{T}}$ & 0.293549 & 0.16255 & $* * *$ \\
\hline$\delta_{M}$ & 0.017197 & 0.00661 & $*$ \\
\hline$\delta_{\mathrm{l}}$ & $-0.31 \bullet 746$ & 0.02820 & \\
\hline$\beta_{t}$ & -52.669242 & 27.04108 & $* * *$ \\
\hline$\beta_{\mathrm{tt}}$ & -4.509470 & 2.35301 & $* * *$ \\
\hline$\theta_{\mathrm{Q}}$ & 17.140204 & 5.33940 & $*$ \\
\hline$\delta_{\mathrm{Q}}$ & -15.554583 & 7.63527 & $* *$ \\
\hline$\delta_{\mathrm{t}}$ & 1.864220 & 7.29511 & \\
\hline$\rho_{\lambda}$ & -10.502779 & 41.85882 & \\
\hline$\rho_{\lambda \lambda}$ & 8.473899 & 6.69468 & \\
\hline
\end{tabular}

Fonte: Dados da pesquisa

Nota: $R^{2}=0,9450$

(a) Definidos conforme equação (8)

* significativo ao nível de 1 .

** significativo ao nível de $5 \%$

*** significativo ao nível de $10 \%$ 
Tabela 10. Estimativa dos parâmetros das funções de parcela, terra e mão-deobra, da agricultura brasileira. Modelo com a constante. Período 1955-1994.

\begin{tabular}{|c|c|c|c|}
\hline Parâmetro ${ }^{(a)}$ & Estimativa & Erro-Padrão & \\
\hline Parcela Terra & & $\mathrm{R}^{2}=0$, & 9550 \\
\hline$\alpha_{1}$ & -4.765590 & 0.49164 & $*$ \\
\hline$\gamma \mathrm{rT}$ & -0.017568 & 0.00170 & $*$ \\
\hline$\gamma_{1 M}$ & 0.000308 & 0.00096 & \\
\hline$\gamma_{\mathrm{Tl}}$ & 0.017260 & 0.01415 & \\
\hline$\sigma_{Q T}$ & 1.167453 & 0.12575 & $*$ \\
\hline$\theta_{\mathrm{r}}$ & -0.321549 & 0.09322 & $*$ \\
\hline$\delta_{\mathrm{T}}$ & 0.293549 & 0.16255 & $* * *$ \\
\hline Parcela Mão-de-obra & & $\mathrm{R}^{2}=0$, & 9540 \\
\hline$\alpha_{2}$ & 5.823782 & 0.50835 & $*$ \\
\hline$\gamma_{L L}$ & -0.014685 & 0.14170 & \\
\hline$\gamma_{M I I}$ & -0.002575 & 0.00079 & $*$ \\
\hline$\gamma_{\mathrm{H}}$ & 0.017260 & 0.01415 & \\
\hline$\sigma_{\mathrm{QL}}$ & -1.170021 & 0.01690 & $*$ \\
\hline$\theta_{\mathrm{l}}$ & 0.330441 & 0.00930 & $*$ \\
\hline$\delta_{1}$ & -0.310746 & 0.02820 & \\
\hline
\end{tabular}

Eonte: Dados da pesquisa

Nota: (a) Definidos conforme equação (9)

* significativo ao nivel de 1 s.

* significativo ao nível de 58

$\star \star \star$ significativo ao nível de 10 
Tabela 11. Estimativa dos parâmetros da função custo translog, restrita, da agricultura brasileira. Modelo sem dummy e sem constante. Período 19551994.

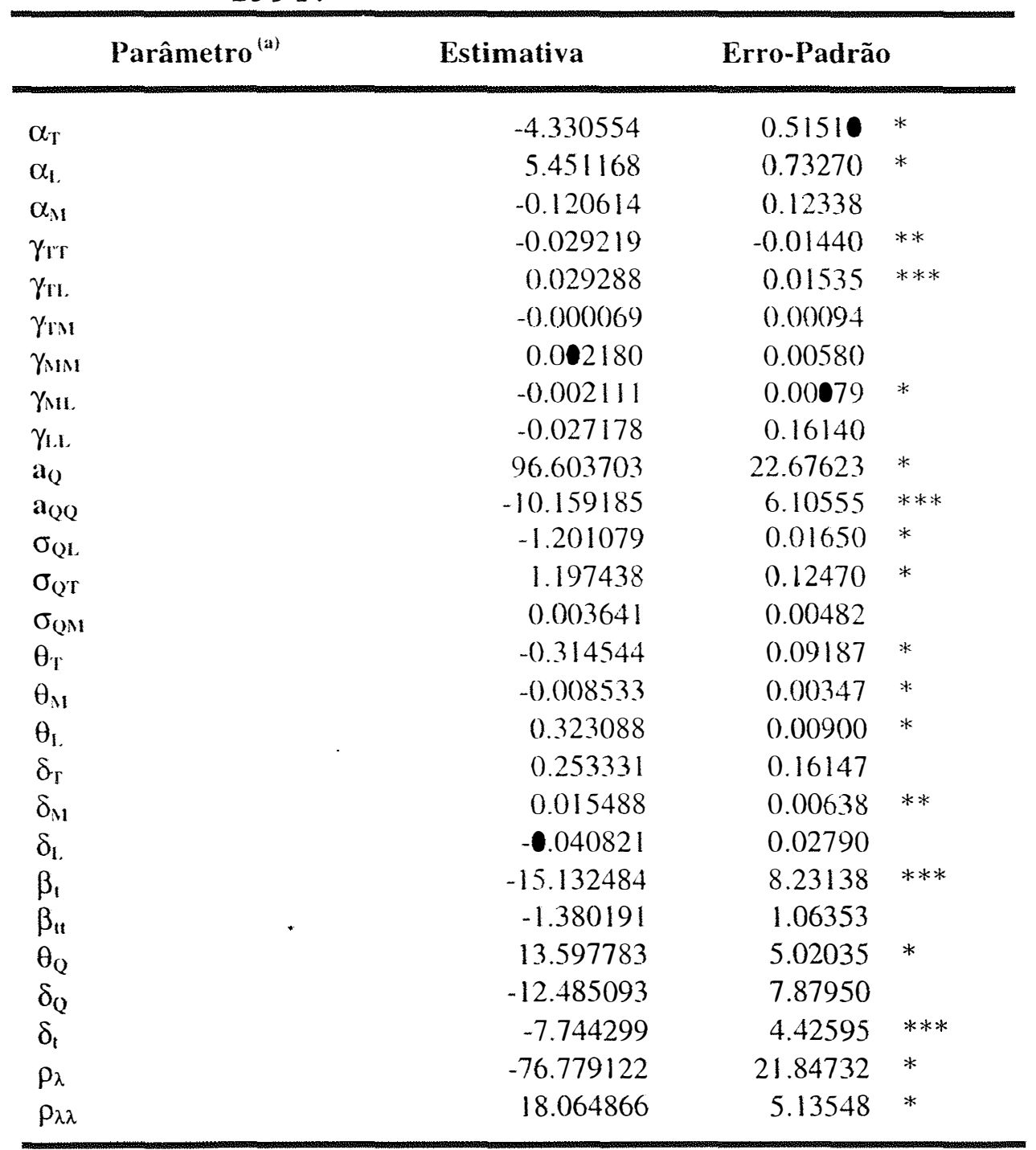

Fonte: Dados da pesquisa

Nota: $R^{2}=0,9229$

(a) Definidos conforme equação (8)

* significativo ao nivel de 18

** significativo ao nível de $5 \%$

*** significativo ao nível de $10 \%$ 
Tabela 12. Estimativa dos parâmetros das funções de parcela, terra e mão-deobra, da agricultura brasileira. Modelo sem a constante. Periodo 1955-1994.

\begin{tabular}{|c|c|c|c|}
\hline Parâmetro ${ }^{(a)}$ & Estimativa & Erro-Padrão & \\
\hline Parcela Terra & & $\mathrm{R}^{2}=0$, & 9564 \\
\hline$\alpha_{1}$ & -4.744238 & 0.48415 & $*$ \\
\hline$\gamma \mathrm{TT}$ & -0.029219 & -0.01440 & $* *$ \\
\hline$\gamma_{\mathrm{TM}}$ & -0.00006944 & 0.0009388 & \\
\hline$\gamma_{\mathrm{Tl}}$ & 0.029288 & 0.01535 & $* * *$ \\
\hline$\sigma_{\mathrm{QT}}$ & 1.197438 & 0.12470 & $*$ \\
\hline$\theta_{\mathrm{r}}$ & -0.314544 & 0.09187 & $*$ \\
\hline$\delta_{\mathrm{T}}$ & 0.253331 & 0.16147 & \\
\hline Parcela Mão-de-obra & & $\mathrm{R}^{2}=0$, & 9556 \\
\hline$\alpha_{1}$ & 5.800811 & 0.50016 & $*$ \\
\hline$\gamma_{1 \mathrm{~L}}$ & -0.027178 & 0.16140 & \\
\hline$\gamma_{\mathrm{MI}}$ & -0.00211039 & 0.0007846 & * \\
\hline$\gamma_{\mathrm{TI}}$ & 0.029288 & 0.01545 & $* * *$ \\
\hline$\sigma_{Q 1}$ & -1.201079 & 0.016 .5 & $*$ \\
\hline$\theta_{1}$ & 0.323088 & 0.0090 & * \\
\hline$\delta_{\mathrm{L}}$ & -0.040821 & 0.0279 & \\
\hline
\end{tabular}

Fonte: Dados da pesquisa

Nota: (a) Definidos conforme equação (9)

* significativo ao nível de 1 :

* * significativo ao nível de 5 c

$\star \star \star$ significativo ao nível de $10 \%$ 
Apêndice 4

ELASTICIDADES E RETORNOS À ESCALA, PERÍODO 19551994 
Tabela 13. Elasticidades-custo e retornos à escala. Período 1955-1994.

\begin{tabular}{|c|c|c|c|}
\hline \multirow[t]{2}{*}{ Ano } & $\begin{array}{l}\text { Elasticidade-Custo em } \\
\text { Relaçãa à Produção }\end{array}$ & Retornos à Escala & $\begin{array}{l}\text { Elasticidade-Custo em } \\
\text { Relaçāo à Capacidade }\end{array}$ \\
\hline & $\varepsilon_{C Q}$ & $\left(1-\varepsilon_{C Q}\right)$ & $\varepsilon_{C \lambda}$ \\
\hline 1955 & 0,40916 & 0,59084 & $-0,32179$ \\
\hline 1956 & 0,43489 & 0,56511 & $-0,31685$ \\
\hline 1957 & 0,43913 & 0,56087 & $-0,32094$ \\
\hline 1958 & 0,45712 & 0,54288 & $-0,32125$ \\
\hline 1959 & 0,45893 & 0.54107 & $-0,32823$ \\
\hline 1960 & 0,46246 & 0,53754 & $-0,32496$ \\
\hline 1961 & 0,47188 & 0,52812 & $-0,32343$ \\
\hline 1962 & 0,47804 & 0,52196 & $-0,32192$ \\
\hline 1963 & 0,48271 & 0,51729 & $-0,31710$ \\
\hline 1964 & 0,48624 & 0,51376 & $-0,31759$ \\
\hline 1965 & 0,48464 & 0,51536 & $-0,32079$ \\
\hline 1966 & 0,49786 & 0,50214 & $-0,31846$ \\
\hline 1967 & 0,49943 & 0,50057 & $-0,31898$ \\
\hline 1968 & 0,50221 & 0,49779 & $-0,31808$ \\
\hline 1969 & 0,50335 & 0,49665 & $-0,31810$ \\
\hline 1970 & 0,50313 & 0,49687 & $-0,31588$ \\
\hline 1971 & 0,49678 & 0,50322 & $-0,31886$ \\
\hline 1972 & 0,49677 & 0,50323 & $-0,31904$ \\
\hline 1973 & 0,50746 & 0,49254 & $-0,31219$ \\
\hline 1974 & 0,50594 & 0,49406 & $-0,30859$ \\
\hline 1975 & 0,49331 & 0,50669 & $-0,31439$ \\
\hline 1976 & 0,49251 & 0,50749 & $-0,31097$ \\
\hline 1977 & 0,47845 & 0,52155 & $-0,32486$ \\
\hline 1978 & 0,48802 & 0,51198 & $-0,32107$ \\
\hline 1979 & 0,48478 & 0,51522 & $-0,32461$ \\
\hline 1980 & 0,48111 & 0,51889 & $-0,32975$ \\
\hline 1981 & 0,48406 & 0,51594 & $-0,33792$ \\
\hline 1982 & 0,48404 & 0,51596 & $-0,33207$ \\
\hline 1983 & 0,50734 & 0,49266 & $-0,34154$ \\
\hline 1984 & 0,49515 & 0,50485 & $-0,33853$ \\
\hline 1985 & 0,48448 & 0,51552 & $-0,34752$ \\
\hline 1986 & 0,49139 & 0,50861 & $-0,33233$ \\
\hline 1987 & 0,48903 & 0,51097 & $-0,34429$ \\
\hline 1988 & 0,48989 & 0,51011 & $-0,34384$ \\
\hline 1989 & 0,48908 & 0,51092 & $-0,34825$ \\
\hline 1990 & 0,51232 & 0,48768 & $-0,35101$ \\
\hline 1991 & 0,51970 & 0,48030 & $-0,35265$ \\
\hline 1992 & 0,51435 & 0,48565 & $-0,35829$ \\
\hline 1993 & 0,53374 & 0,46626 & $-0,36240$ \\
\hline 1994 & 0,51701 & 0,48299 & $-0,36260$ \\
\hline
\end{tabular}

Fonte: Dados da pesquisa

Nota: Valores calculados com base no modelo estimado com a constante e sem a dumny. 


\section{Apêndice 5}

ESTATISTICAS DO MODELO SUR INTERATIVO 


\section{Modelo com variável dummy}

Estimação de 3 equações pelo Método ITSUR (CUSTO, MAO-DEOBRA E TERRA), com imposição das sete restrições aos parâmetros. Foi utilizada a rotina do SAS

MODEL Procedure

Model Summary

Model Variables 41

Parameters 41

Equations 3

Number of Statements 3

NOTE: The parameter A113 is shared by 2 of the equations to be estimated.

NOTE: The parameter A114 is shared by 2 of the equations to be estimated.

NOTE: The parameter Al16 is shared by all 3 of the equations to be estimated.

NOTE: The parameter A119 is shared by 2 of the equations to be estimated.

NOTE: The parameter Al20 is shared by all 3 of the equations to be estimated.

NOTE: The parameter A123 is shared by 2 of the equations to be estimated.

NOTE: The parameter Al24 is shared by all 3 of the equations to be estimated.

NOTE: The parameter A129 is shared by 2 of the equations to be estimated.

NOTE: The parameter A130 is shared by all 3 of the equations to be estimated.

The 3 Equations to Estimate are:

LCUSTO $=F(A 10(1)$, DUMMY1 (DCONCA'T), A11 (LTREND), A12(LINDQT), A13, A14, A17 (LINDCAP), A18(PROD2), A113, A114, A116, A119, A120, A123, A124, A127 (ANO_PROD), A128(ANO2), A129, A130, A133(CAP_PROD), A134(CAP_ANO),A135(CAP2))

STERRA $=F(B 10(1)$, DUMMY2 (DCONCAT), A113, A116, A120 (LINDQT), A124 (LTREND), A130 (LINDCAP))

$\mathrm{SMDO}=\mathrm{F}(\mathrm{C} 10(1), \mathrm{DUMMY} 3$ (DCONCAT), A114, A116, A119, A120, A123, A124, A129, A130)

ITSUR Estimation

Summary

Dataset Option Dataset

DATA $=\quad$ DADOS

OUT $=$ - SAIDA

OUTSUSED $=$ SMATRIX

Parameters Estimated 26

Minimization Summäry

Method

GAUSS

Iterations

Final Convergence Criteria

$\begin{array}{ll}R & 0.0006954\end{array}$

PPC (DUMMY1) $\quad 0.101566$

RPC (DUMMY1) $\quad 0.225091$

Object $\quad 0.00002426$

Trace (S) $\quad 0.0267558$

Objective Value 4.10379222

S $\quad 0.00558082$ 
Observations Processed

Read 40

Solved 40

ITSUR Estimation

Nonlinear ITSUR Summary of Residual Errors DF DF

$\begin{array}{lrlrrrrr}\text { Equation } & \text { Model } & \text { Error } & \text { SSE } & \text { MSE } & \text { Root MSE } & \text { R-Square } & \text { Adj R-Sq } \\ \text { LCUSTO } & 16.83 & 23.17 & 0.46857 & 0.02023 & 0.14222 & 0.9474 & 0.9114 \\ \text { STERRA } & 3.833 & 36.17 & 0.11403 & 0.0031529 & 0.05615 & 0.9555 & 0.9520 \\ \text { SMDO } & 5.333 & 34.67 & 0.11706 & 0.0033768 & 0.05811 & 0.9545 & 0.9488\end{array}$

Nonlinear ITSUR Parameter Estimates

$\begin{array}{lrrrr}\text { Parameter } & \text { Estimate } & \begin{array}{r}\text { Approx. } \\ \text { Std Err }\end{array} & \begin{array}{r}\text { 'T' } \\ \text { Ratio }\end{array} & \begin{array}{r}\text { Approx. } \\ \text { Prob }|\mathrm{T}|\end{array} \\ \text { A10 } & -122.745088 & 78.36928 & -1.57 & 0.1309 \\ \text { B10 } & -4.545131 & 0.73322 & -6.20 & 0.0001 \\ \text { C10 } & 5.609635 & 0.75878 & 7.39 & 0.0001 \\ \text { DUMMY1 } & 0.00166225 & 0.15236 & 0.01 & 0.9914 \\ \text { DUMMY2 } & 0.019391 & 0.04876 & 0.40 & 0.6932 \\ \text { DUMMY3 } & -0.018935 & 0.05046 & -0.38 & 0.7097 \\ \text { A11 } & -52.343545 & 27.28200 & -1.92 & 0.0675 \\ \text { A12 } & 109.597787 & 27.15424 & 4.04 & 0.0005 \\ \text { A13 } & -0.061254 & 0.12013 & -0.51 & 0.6150 \\ \text { A14 } & -4.207043 & 0.76177 & -5.52 & 0.0001 \\ \text { A17 } & -6.714412 & 42.50754 & -0.16 & 0.8759 \\ \text { A18 } & -9.953830 & 6.23508 & -1.60 & 0.1240 \\ \text { A113 } & 0.00012776 & 0.0009909 & 0.13 & 0.8983 \\ \text { A114 } & -0.00252278 & 0.0008247 & -3.06 & 0.0047 \\ \text { A116 } & 0.020180 & 0.01510 & 1.34 & 0.1912 \\ \text { A119 } & 0.00457684 & 0.0087507 & 0.52 & 0.6049 \\ \text { A120 } & 1.103010 & 0.22036 & 5.01 & 0.0001 \\ \text { A123 } & -0.00952239 & 0.0043203 & -2.20 & 0.0356 \\ \text { A124 } & -0.297744 & 0.10930 & -2.72 & 0.0105 \\ \text { A127 } & 16.711448 & 5.40884 & 3.09 & 0.0052 \\ \text { A128 } & -4.520155 & 2.37458 & -1.90 & 0.0696 \\ \text { A129 } & 0.017148 & 0.0068356 & 2.51 & 0.0180 \\ \text { A130 } & 0.287254 & 0.16501 & 1.74 & 0.0916 \\ \text { A133 } & -18.005995 & 8.71238 & -2.07 & 0.0502 \\ \text { A134 } & 2.178502 & 7.37851 & 0.30 & 0.7705 \\ \text { A135 } & 9.160917 & 6.88638 & 1.33 & 0.1965 \\ & & & & \end{array}$

Number of Observations

Used

Missing
Statistics for System

Objective $\quad 4.1038$

objective*N 164.1517

Covariance of Residuals

$\begin{array}{lrrr}\text { S } & \text { LCUSTO } & \text { STERRA } & \text { SMDO } \\ \text { LCUSTO } & 0.0202 & -0.002869 & 0.002920 \\ \text { STERRA } & -0.002869 & 0.003153 & -0.003263 \\ \text { SMDO } & 0.002920 & -0.003263 & 0.003377\end{array}$




\section{Modelo sem variável dummy}

Estimação de 3 equações pelo Método ITSUR (CUSTO, MAO-DEOBRA E TERRA), com imposição das sete restrições aos parâmetros. Foi utilizada a rotina do SAS

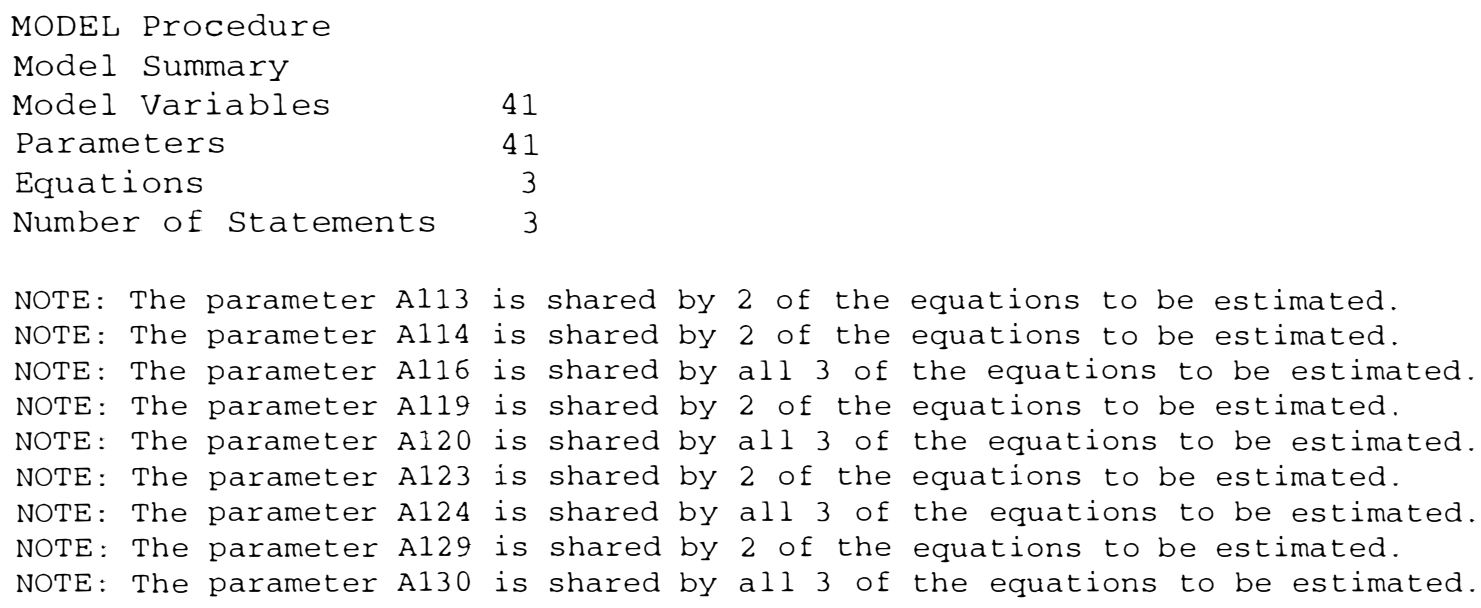

The 3 Equations to Estimate are:

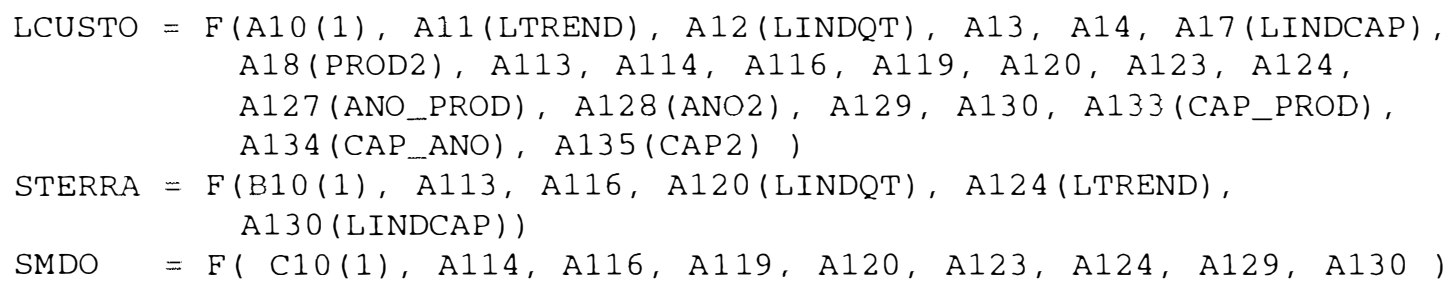


ITSUR Estimation

Nonlinear ITSUR Summary of Residual Errors DF $\quad D F$

Equation Model Error

$\begin{array}{rr}\text { SSE } & \text { MSE } \\ 0.48957 & 0.02026 \\ 0.11541 & 0.0031052 \\ 0.11842 & 0.0033203\end{array}$

Root MSE

0.14233

R-Square

0.05572

0.9450

Adj $R-S q$

LCUSTO

$\begin{array}{lll}15.83 & 24.17 \\ 2.833 & 37.17\end{array}$

0.11842

0.05762

0.9550

0.9112

SMDO

4.33335 .67

0.0033203

0.9540

0.9528

0.9497

Nonlinear ITSUR Parameter Estimates

$\begin{array}{lr}\text { Parameter } & \text { Estimate } \\ \text { A10 } & -121.288364 \\ \text { B10 } & -4.765590 \\ \text { C10 } & 5.823782 \\ \text { A11 } & -52.669242 \\ \text { A12 } & 113.130501 \\ \text { A13 } & -0.057066 \\ \text { A14 } & -4.436052 \\ \text { A17 } & -10.502779 \\ \text { A18 } & -11.777058 \\ \text { A113 } & 0.00030823 \\ \text { A114 } & -0.00257468 \\ \text { A116 } & 0.017260 \\ \text { A119 } & 0.00256810 \\ \text { A120 } & 1.167453 \\ \text { A123 } & -0.00889216 \\ \text { A124 } & -0.321549 \\ \text { A127 } & 17.140204 \\ \text { A128 } & -4.509470 \\ \text { A129 } & 0.017197 \\ \text { A130 } & 0.293549 \\ \text { A133 } & -15.554583 \\ \text { A134 } & 1.864220 \\ \text { A135 } & 8.473899 \\ & \end{array}$

Number of Observations

Used

Missing

40

0 .
Approx.

Std Err

77.65296

0.49164

0.50835

27.04108

26.60198

0.11647

0.51355

41.85882

5.58716

0.0009549

0.0007879

0.01415

0.0050049

0.12575

0.0036146

0.09322

5.33940

2.35301

0.0066125

0.16255

7.63527

7.29511

6.69468
' $T$ ' Approx.

Ratio Prob $>|\mathrm{T}|$

$\begin{array}{ll}-1.56 & 0.1314\end{array}$

$\begin{array}{ll}-9.69 & 0.0001\end{array}$

$11.46 \quad 0.0001$

$\begin{array}{ll}-1.95 & 0.0632\end{array}$

$\begin{array}{ll}4.25 & 0.0003\end{array}$

$\begin{array}{rl}-0.49 & 0.6286\end{array}$

$\begin{array}{ll}-8.64 & 0.0001\end{array}$

$\begin{array}{ll}-0.25 & 0.8040\end{array}$

$\begin{array}{ll}-2.11 & 0.0457\end{array}$

$0.32 \quad 0.7490$

$\begin{array}{ll}-3.27 & 0.0027\end{array}$

$\begin{array}{ll}1.22 & 0.2315\end{array}$

$0.51 \quad 0.6116$

$9.28 \quad 0.0001$

$\begin{array}{ll}-2.46 & 0.0199\end{array}$

$-3.45 \quad 0.0016$

$\begin{array}{ll}3.21 & 0.0037\end{array}$

$\begin{array}{ll}-1.92 & 0.0673\end{array}$

$2.60 \quad 0.0143$

$\begin{array}{ll}1.81 & 0.0804\end{array}$

$-2.04 \quad 0.0528$

$0.26 \quad 0.8005$

$\begin{array}{ll}1.27 & 0.2177\end{array}$

Covariance of Residuals

$\begin{array}{lrrr}\text { S } & \text { LCUSTO } & \text { STERRA } & \text { SMDO } \\ \text { LCUSTO } & 0.0203 & -0.002960 & 0.003012 \\ \text { STERRA } & -0.002960 & 0.003105 & -0.003211 \\ \text { SMDO } & 0.003012 & -0.003211 & 0.003320\end{array}$

Statistics for System

Objective 4.1803

objective*N 167.2110 


\section{Modelo sem variável dummy e sem constante}

Estimação de 3 equações pelo Método ITSUR (CUSTO, MAO-DEOBRA E TERRA), com imposição das sete restrições aos parâmetros. Foi utilizada a rotina do SAS

$\begin{array}{lr}\text { MODEL Procedure } & \\ \text { Model Summary } & 41 \\ \text { Model Variables } & 41 \\ \text { Parameters } & 3 \\ \text { Equations } & 3\end{array}$

NOTE: The parameter A113 is shared by 2 of the equations to be estimated. NOTE: The parameter A114 is shared by 2 of the equations to be estimated. NOTE: The parameter A116 is shared by all 3 of the equations to be estimated. NOTE: The parameter A119 is shared by 2 of the equations to be estimated. NOTE: The parameter A120 is shared by all 3 of the equations to be estimated. NOTE: The parameter A123 is shared by 2 of the equations to be estimated. NOTE: The parameter A124 is shared by all 3 of the equations to be estimated. NOTE: The parameter A129 is shared by 2 of the equations to be estimated. NOTE: The parameter A130 is shared by all 3 of the equations to be estimated.

The 3 Equations to Estimate are:

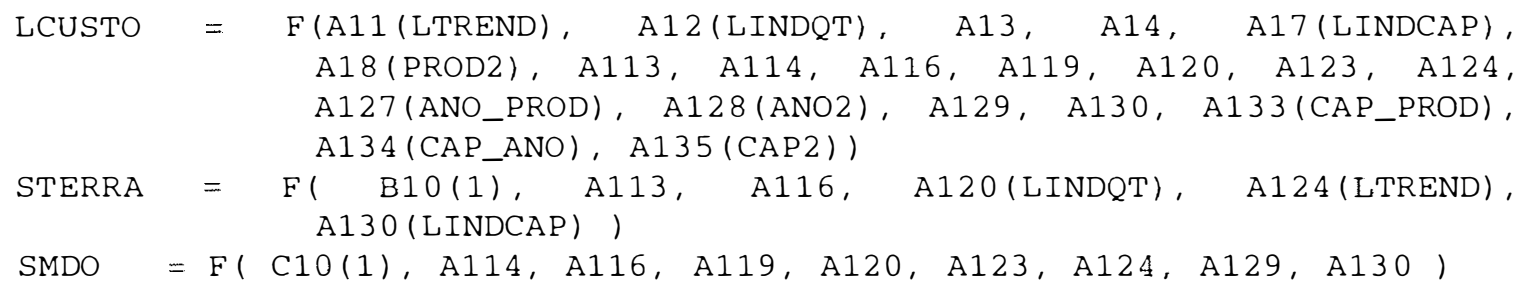

ITSUR Estimation

Summary

Dataset Option Dataset

DATA $=$

DADOS

OUT $=$

SAIDA

OUTSUSED $=$ SMATRIX

Parameters Estimated 22

Minimization Summary

Method

GAUSS

Iterations 20

Final Convergence Criteria

$R$

PPC (A113)

0.00087277

0.036906

Object $\quad 0.00003304$

Trace (S) $\quad 0.03345942$

Objective value 4.32835736

S 0.00448709

Observations Processed

Read 40

Solved 40 


\begin{tabular}{|c|c|c|c|c|c|c|c|}
\hline Nonline & $c_{\mathrm{DF}}^{\mathrm{ITSU}}$ & $\begin{array}{l}\text { R Sumn } \\
\text { DF }\end{array}$ & of Res & lual Error & & & \\
\hline Equation & Model & Error & SSE & MSE & Root MSE & R-Square & Adj $R-S q$ \\
\hline LCUSTO & 14.83 & 25.17 & 0.68577 & 0.02725 & 0.16507 & 0.9229 & 0.8806 \\
\hline STERRA & 2.833 & 37.17 & 0.11165 & 0.0030040 & 0.05481 & 0.9564 & 0.9543 \\
\hline SMDO & 4.333 & 35.67 & 0.11436 & 0.0032064 & 0.05663 & 0.9556 & 0.9514 \\
\hline
\end{tabular}

Nonlinear ITSUR Parameter Estimates

$\begin{array}{lrrrr}\text { Parameter } & \text { Estimate } & \begin{array}{r}\text { Approx. } \\ \text { Std Err }\end{array} & \begin{array}{r}\text { 'T' } \\ \text { Ratio }\end{array} & \begin{array}{r}\text { Approx. } \\ \text { Prob>|T| }\end{array} \\ \text { B10 } & -4.744238 & 0.48415 & -9.80 & 0.0001 \\ \text { C10 } & 5.800811 & 0.50016 & 11.60 & 0.0001 \\ \text { A11 } & -15.132484 & 8.23138 & -1.84 & 0.0779 \\ \text { A12 } & 96.603703 & 22.67623 & 4.26 & 0.0003 \\ \text { A13 } & -0.120614 & 0.12338 & -0.98 & 0.3377 \\ \text { A14 } & -4.330554 & 0.51210 & -8.46 & 0.0001 \\ \text { A17 } & -76.779122 & 21.84732 & -3.51 & 0.0017 \\ \text { A18 } & -10.159185 & 6.10555 & -1.66 & 0.1086 \\ \text { A113 } & -0.00006944 & 0.0009388 & -0.07 & 0.9415 \\ \text { A114 } & -0.00211039 & 0.0007846 & -2.69 & 0.0116 \\ \text { A116 } & 0.029288 & 0.01535 & 1.91 & 0.0651 \\ \text { A119 } & 0.00364130 & 0.0048219 & 0.76 & 0.4560 \\ \text { A120 } & 1.197438 & 0.12470 & 9.60 & 0.0001 \\ \text { A123 } & -0.00853313 & 0.0034663 & -2.46 & 0.0198 \\ \text { A124 } & -0.314544 & 0.09187 & -3.42 & 0.0017 \\ \text { A127 } & 13.597783 & 5.02035 & 2.71 & 0.0120 \\ \text { A128 } & -1.380191 & 1.06353 & -1.30 & 0.2062 \\ \text { A129 } & 0.015488 & 0.0063759 & 2.43 & 0.0213 \\ \text { A130 } & 0.253331 & 0.16147 & 1.57 & 0.1262 \\ \text { A133 } & -12.485093 & -7.87950 & -1.58 & 0.1256 \\ \text { A134 } & -7.744299 & 4.42595 & -1.75 & 0.0924 \\ \text { A135 } & 18.064866 & 5.13548 & 3.52 & 0.0017\end{array}$

Number of Observations Used

Missing
Statistics for System Objective $\quad 4.3284$ Objective*N 173.1343

Covariance of Residuals

$\begin{array}{lrrr}\text { S } & \text { LCUSTO } & \text { STERRA } & \text { SMDO } \\ \text { LCUSTO } & 0.0272 & -0.003569 & 0.003631 \\ \text { STERRA } & -0.003569 & 0.003004 & -0.003103 \\ \text { SMDO } & 0.003631 & -0.003103 & 0.003206\end{array}$

